\title{
Protocol for Monitoring Metals in Ozark National Scenic Riverways, Missouri: Version 1.0
}

Open-File Report 2008-1269

U.S. Department of the Interior U.S. Geological Survey 
Cover Photographs. Shells of Asian clams (Corbicula fluminea) on the bottom of a stream (background). Photograph by B. Poulton, U.S. Geological Survey. Asian clams, Corbicula fluminea (top left inset). Photograph by B. Poulton, U.S. Geological Survey. The Current River at Cave Spring (right inset). Photograph by D. Hardesty, U.S. Geological Survey. Golden crayfish, Orconectes luteus (bottom left inset). Photograph courtesy of R. DiStefano, Missouri Department of Conservation. 


\section{Protocol for Monitoring Metals in Ozark National Scenic Riverways, Missouri: Version 1.0}

By Christopher J. Schmitt, William G. Brumbaugh, John M. Besser, Jo Ellen Hinck, David E. Bowles, Lloyd W. Morrison, and Michael H. Williams

Prepared in cooperation with the National Park Service

Open-File Report 2008-1269 


\section{U.S. Department of the Interior DIRK KEMPTHORNE, Secretary}

\section{U.S. Geological Survey \\ Mark D. Myers, Director}

\section{U.S. Geological Survey, Reston, Virginia: 2008}

For product and ordering information:

World Wide Web: http://www.usgs.gov/pubprod

Telephone: 1-888-ASK-USGS

For more information on the USGS - the Federal source for science about the Earth, its natural and living resources, natural hazards, and the environment:

World Wide Web: http://www.usgs.gov

Telephone: 1-888-ASK-USGS

Any use of trade, product, or firm names is for descriptive purposes only and does not imply endorsement by the U.S. Government.

Although this report is in the public domain, permission must be secured from the individual copyright owners to reproduce any copyrighted materials contained within this report.

Suggested citation:

Schmitt, C.J., Brumbaugh, W.G., Besser, J.M., Hinck, J.E., Bowles, D.E., Morrison, L.W., and Williams, M.H., 2008,

Protocol for monitoring metals in Ozark National Scenic Riverways, Missouri: Version 1.0: U.S. Geological Survey Open-File Report 2008-1269, 42 p. 


\section{Contents}

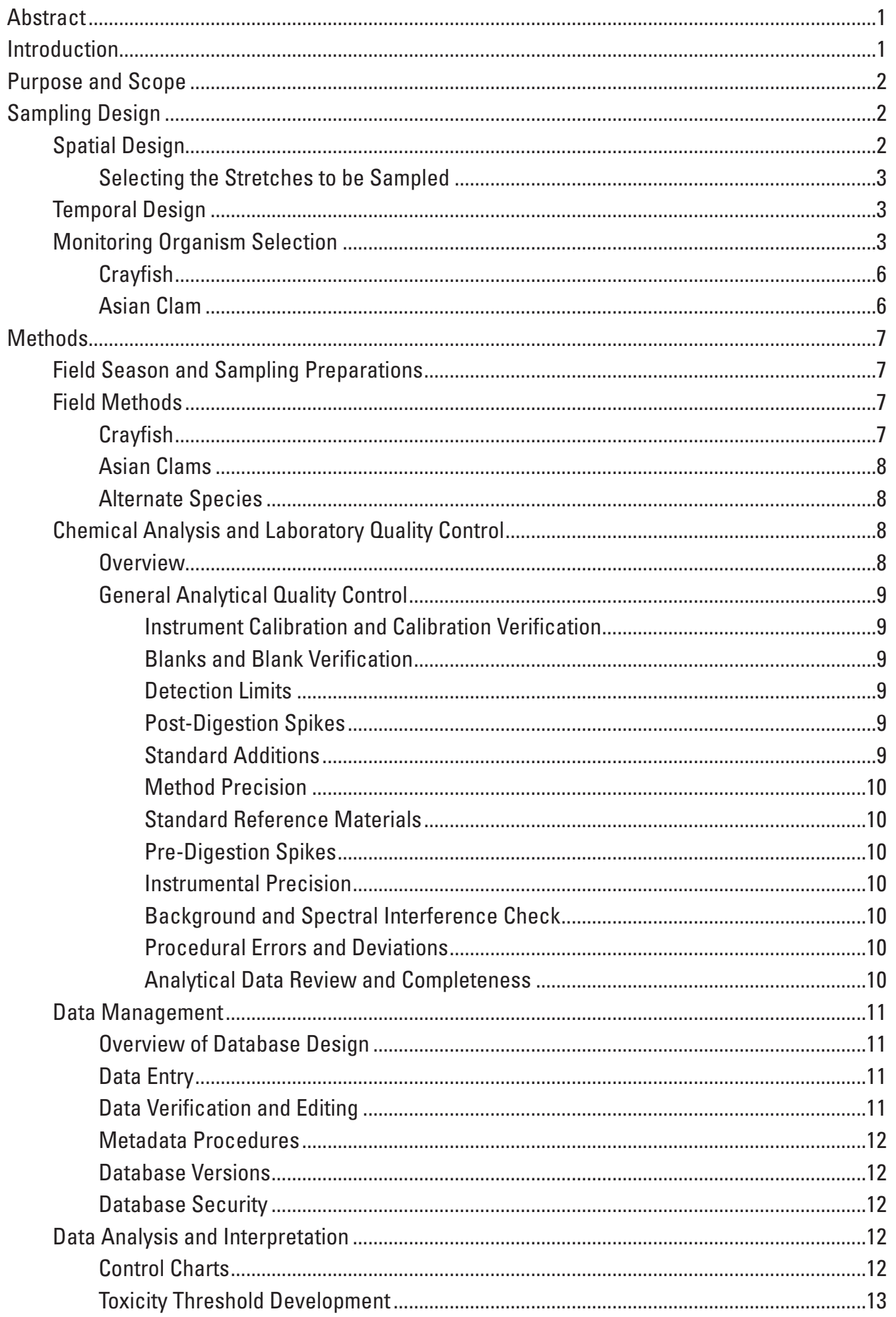


Assumptions and Uncertainties ...................................................................................

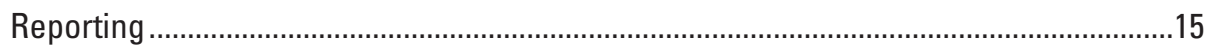

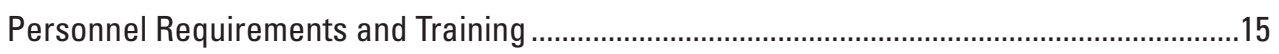

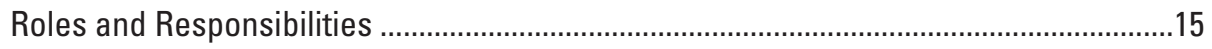

Qualifications and Training......................................................................................15

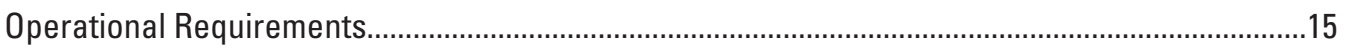

Annual Workload and Field Schedule ...............................................................................15

Facility, Equipment, and Personnel Needs ........................................................................16

Procedure for Revising the Protocol and Archiving Previous Versions of the Protocol .................16

Standard Operating Procedure 1: Preparation for Sampling, Version 1.0 (July 28, 2008)..............18

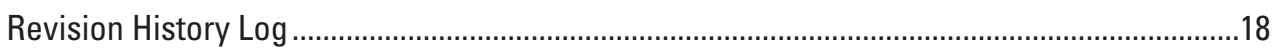

General Preparation and Review..................................................................................18

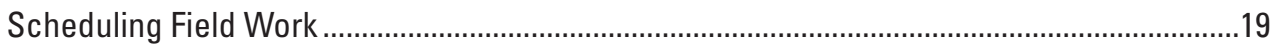

Organizing Supplies and Equipment...............................................................................19

Pre-Sampling Procedures ...............................................................................................19

Standard Operating Procedure 2: Collecting, Processing, and Preparing Samples of Crayfish

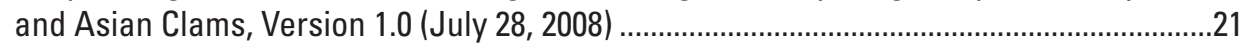

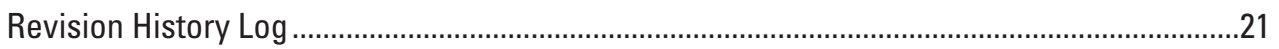

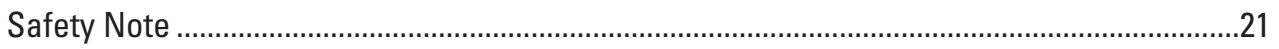

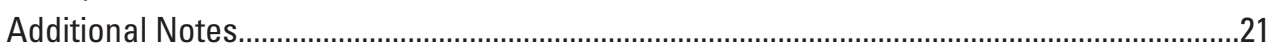

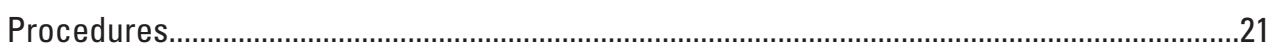

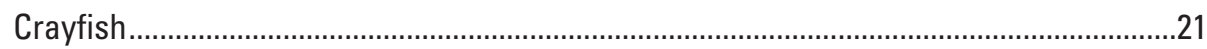

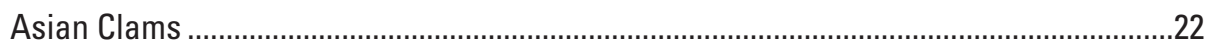

Standard Operating Procedure 3: After the Field Collections, Version 1.0 (July 28, 2008) .............24

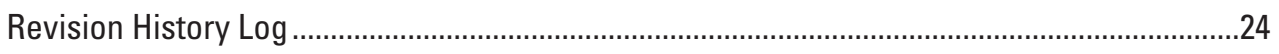

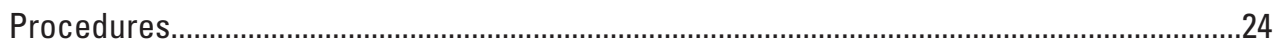

Standard Operating Procedure 4: Data Management, Version 1.0 (July 28, 2008) .........................25

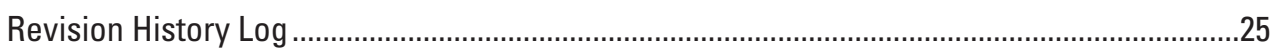

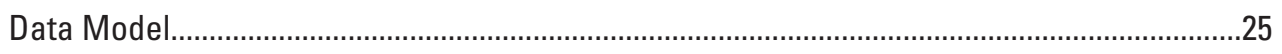

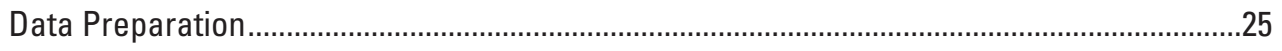

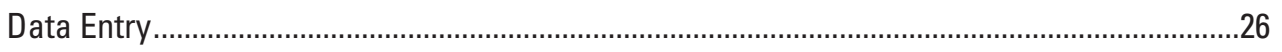

Standard Operating Procedure 5: Data Analysis, Version 1.0 (July 28, 2008) ...............................27

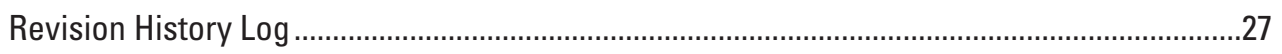

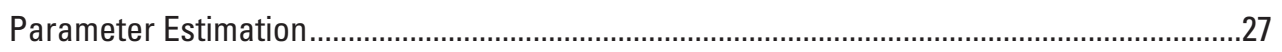

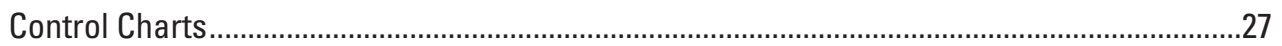

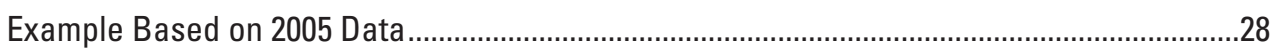

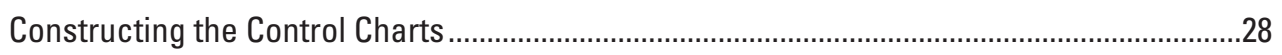

Standard Operating Procedure 6: Reporting, Version 1.0 (July 28, 2008) ......................................30

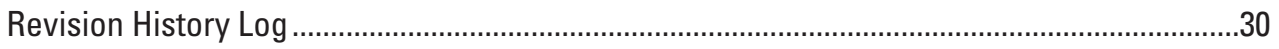

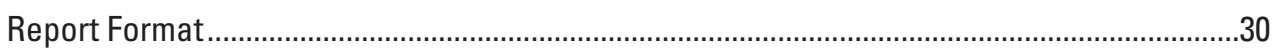

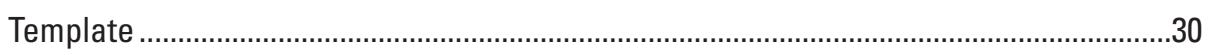

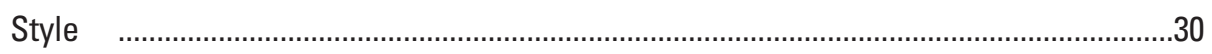

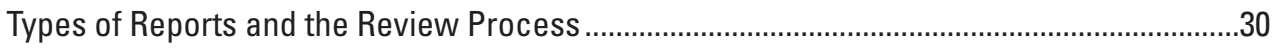

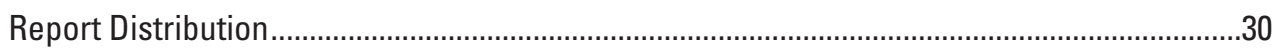

Standard Operating Procedure 7: After the Field Season, Version 1.0 (July 28, 2008)....................31

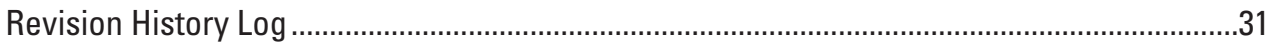




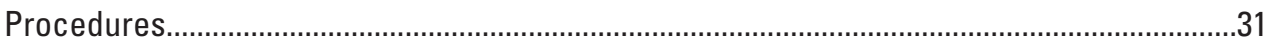

Standard Operating Procedure 8: Revising the Protocol, Version 1.0 (July 28, 2008) .....................32

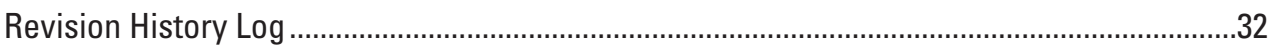

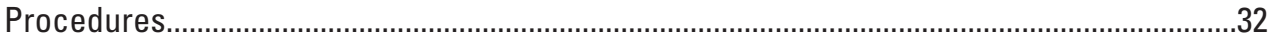

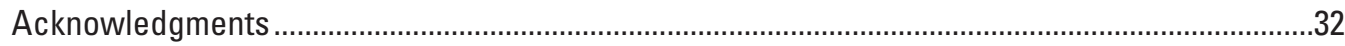

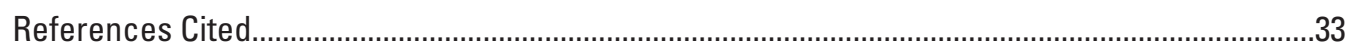

Appendix 1. Invertebrate field data form, sample labels, and chain-of-custody record................39

\section{Figures}

1. Map of Ozark National Scenic Riverways (ONSR)...........................................................

2. Example control chart for tracking concentrations of metals in crayfish and Asian

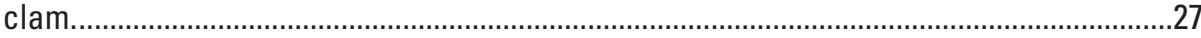

\section{Tables}

1. Reaches and stretches selected for monitoring ............................................................

2. Estimated personnel, travel, and analytical resources, per collection ............................16

3. Field equipment and supplies for collecting crayfish and Asian clams ...........................20

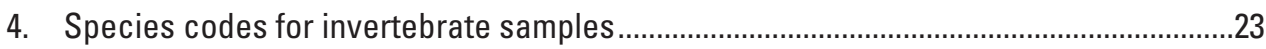

5. No observed adverse effect level toxicity reference values for metals in mammals and birds, and maximum 2005 concentrations in crayfish (Orconectes luteus) and Asian clam (Corbicula fluminea) from Ozark National Scenic Riverways ................................28

6. No-effect hazard concentrations and safety factors of metals in crayfish (Orconectes spp.) and Asian clam (Corbicula fluminea) for receptor wildlife species 
Conversion Factors

\begin{tabular}{|c|c|c|}
\hline Multiply & By & To obtain \\
\hline \multicolumn{3}{|c|}{ Length } \\
\hline centimeter $(\mathrm{cm})$ & 0.3937 & inch (in.) \\
\hline millimeter (mm) & 0.03937 & inch (in.) \\
\hline meter $(\mathrm{m})$ & 3.281 & foot $(\mathrm{ft})$ \\
\hline kilometer (km) & 0.6214 & mile (mi) \\
\hline meter $(\mathrm{m})$ & 1.094 & yard (yd) \\
\hline \multicolumn{3}{|c|}{ Area } \\
\hline square meter $\left(\mathrm{m}^{2}\right)$ & 0.0002471 & acre \\
\hline hectare (ha) & 2.471 & acre \\
\hline hectare (ha) & 0.003861 & square mile $\left(\mathrm{mi}^{2}\right)$ \\
\hline square kilometer $\left(\mathrm{km}^{2}\right)$ & 0.3861 & square mile $\left(\mathrm{mi}^{2}\right)$ \\
\hline \multicolumn{3}{|c|}{ Flow rate } \\
\hline cubic meter per second $\left(\mathrm{m}^{3} / \mathrm{s}\right)$ & 22.83 & million gallons per day (Mgal/d) \\
\hline \multicolumn{3}{|c|}{ Mass } \\
\hline $\operatorname{gram}(\mathrm{g})$ & 0.03527 & ounce, avoirdupois (oz) \\
\hline milligram (mg) & 0.000035 & ounce (oz) \\
\hline kilogram (kg) & 2.205 & pound avoirdupois (lb) \\
\hline
\end{tabular}

Temperature in degrees Celsius $\left({ }^{\circ} \mathrm{C}\right)$ may be converted to degrees Fahrenheit $\left({ }^{\circ} \mathrm{F}\right)$ as follows:

$$
{ }^{\circ} \mathrm{F}=\left(1.8 \times^{\circ} \mathrm{C}\right)+32
$$

Temperature in degrees Fahrenheit $\left({ }^{\circ} \mathrm{F}\right)$ may be converted to degrees Celsius $\left({ }^{\circ} \mathrm{C}\right)$ as follows:

$$
{ }^{\circ} \mathrm{C}=\left({ }^{\circ} \mathrm{F}-32\right) / 1.8
$$

Horizontal coordinate information is referenced to the North American Datum of 1983 (NAD 83)

Concentrations of chemical constituents are given in micrograms per gram $(\mu \mathrm{g} / \mathrm{g}$; parts-permillion). 


\title{
Protocol for Monitoring Metals in Ozark National Scenic Riverways, Missouri: Version 1.0
}

\author{
By Christopher J. Schmitt', William G. Brumbaugh', John M. Besser ${ }^{1}$, Jo Ellen Hinck' ${ }^{1}$ David E. Bowles ${ }^{2}$, \\ Lloyd W. Morrison², and Michael H. Williams ${ }^{2}$
}

\begin{abstract}
The National Park Service is developing a monitoring plan for the Ozark National Scenic Riverways in southeastern Missouri. Because of concerns about the release of lead, zinc, and other metals from lead-zinc mining to streams, the monitoring plan will include mining-related metals. After considering a variety of alternatives, the plan will consist of measuring the concentrations of cadmium, cobalt, lead, nickel, and zinc in composite samples of crayfish (Orconectes luteus or alternate species) and Asian clam (Corbicula fluminea) collected periodically from selected sites. This document, which comprises a protocol narrative and supporting standard operating procedures, describes the methods to be employed prior to, during, and after collection of the organisms, along with procedures for their chemical analysis and quality assurance; statistical analysis, interpretation, and reporting of the data; and for modifying the protocol narrative and supporting standard operating procedures. A list of supplies and equipment, data forms, and sample labels are also included. An example based on data from a pilot study is presented.
\end{abstract}

\section{Introduction}

Ozark National Scenic Riverways (ONSR) is situated within the Ozark Plateau in southeastern Missouri. Managed by the National Park Service (NPS), ONSR comprises approximately 33,265 hectares and includes $216 \mathrm{~km}$ of the Current River and the Jacks Fork. Famous for its large freshwater springs, caves, spring-fed rivers, and recreational opportunities, ONSR lies in a landscape of oak-hickory forest and pastoral river valleys. Canoeing, camping, and sport fishing are especially popular recreational activities. The Current River and Jacks Fork support populations of the Ozark hellbender (Cryptobranchus alleganiensis bishopi), a large, predatory salamander considered endangered in Missouri that

\footnotetext{
${ }^{1}$ U.S. Geological Survey

${ }^{2}$ National Park Service
}

has been proposed for Federal listing (Missouri Department of Conservation, 2007).

The highly mineralized Ozark Plateau contains economically significant lead-zinc deposits of the Mississippi Valley Type (Goldhaber and others, 1995). Surface lead-zinc deposits were discovered by early French explorers; these and subsequently discovered deposits have been exploited at varying levels of intensity since the early 1700s. Advances in mining technology facilitated deep mining, which was and remains focused in two southeast Missouri districts: the "Old Lead Belt," primarily located in Washington and St. Francois counties, was active from about 1700 until the early 1970s (Schmitt and others, 1984; Gale and others, 2004); and the "New Lead Belt," primarily located in Crawford, Iron, and Reynolds counties, which became active in the 1960s and where lead and zinc are still mined (Wixson and Jennett, 1975; Wixson, 1978; Proctor, 1984; Imes, 2002). These metals, along with other potentially toxic byproduct metals including cadmium, cobalt, and nickel, are released to the environment from mining and ore processing.

Most mining and ore processing in the New Lead Belt occurs on lands that formerly were part of the Mark Twain National Forest. The southernmost extent of the New Lead Belt is located only about $32 \mathrm{~km}$ northeast of ONSR. Additional potentially exploitable deposits have been discovered within the Mark Twain National Forest in Shannon County (Imes, 2002). Although the exploration area lies in the surfacewater drainage of the Eleven Point River, it is relevant to ONSR because it is in the ground-water recharge area of Big Spring, an important feature within ONSR that contributes substantially to flows in the Current River (Imes, 2002; Imes and others, 2007).

Ambient concentrations of lead and other metals from natural sources in the Ozarks have been augmented by releases from mining and ore processing activities. Karst features such as sinkholes, conduits, and springs in the area may facilitate the transport of mining-associated contaminants from runoff and discharges (Imes, 2002; Imes and others, 2007). Although lead does not accumulate to high concentrations in aquatic organisms, elevated concentrations and effects such as biochemical responses in fish and altered benthic fish and macro-invertebrate community composition have been 
associated with the release of metals from the Old Lead Belt and New Lead Belt (Schmitt and Finger, 1982, 1987; Whelan, 1983; Schmitt and others, 1984, 1987, 1992, 1993, 2005, 2006, 2007a, 2007b, 2007c; Dwyer and others, 1988; Gale and others, 2004; Brumbaugh and others, 2005; Besser and others, 2007a; Allert and others, 2008). A human consumption advisory also has been issued for fish from some mining-contaminated streams because of elevated lead concentrations (Missouri Department of Health and Senior Services, 2008). ONSR managers have expressed a need to define and track concentrations of lead and other potentially toxic metals. These needs may become more acute if additional economically significant lead-zinc deposits are located and exploited. Out of concern for human and ecological health, monitoring would enable ONSR to take all necessary actions to meet applicable federal, state, and local laws and regulations and better support the management goals of ONSR in accordance with the park's enabling legislation and NPS management policies.

\section{Purpose and Scope}

The National Parks Omnibus Management Act of 1998 and NPS policy require that park managers know the condition of natural resources under their stewardship, and monitor long-term trends in those resources to fulfill the agency mission of conserving parks unimpaired. Accordingly, a comprehensive monitoring plan developed by the Heartland Inventory and Monitoring Network (HTLN) of the NPS calls for periodic assessments of stream condition at ONSR (DeBacker and others, 2005). The U.S. Geological Survey (USGS), in cooperation with HTLN, developed this protocol for monitoring metals in waters of ONSR. The specific goals of monitoring conducted under this protocol are to: determine the current environmental concentrations of lead and other metals in the rivers of ONSR to provide reference points for future comparisons; determine the natural variability of metals concentrations in the biota inhabiting these streams; and document changes in the environmental concentrations of lead and other metals to better understand the dynamic nature and condition of ONSR streams and risks to biota.

Monitoring will consist of measuring concentrations of metals in samples of invertebrates collected periodically from ONSR. A pilot study using a draft version of this protocol was conducted to document baseline (2005) concentrations of lead and other metals (Schmitt and others, 2007b). Version 1.0 of the protocol reflects the results of and experience gained from the pilot study. Future monitoring will determine if concentrations are increasing and if riparian wildlife, aquatic organisms, or both are exposed to potentially toxic concentrations of lead or other metals. Monitoring conducted under related protocols will determine the status of fish and benthic macroinvertebrate communities (Bowles and others, 2007; Petersen and others, 2007).
The protocol is comprised a protocol narrative, eight standard operating procedures (SOPs), and three appendices (at the back of the report). This organization will facilitate modification of individual SOPs by the NPS.

\section{Sampling Design}

An integrated aquatic monitoring plan is being developed for ONSR that will include the co-location and potential co-visitation of sites to document "vital signs" (Fancy, 2001). Vital signs are measurement variables selected to reflect the condition of National Parks. The framework for the ONSR monitoring plan was conceived during a workshop of biologists, statisticians, and administrators held in July 2004 (McDonald, 2004). The protocol described here focuses on contamination from lead-zinc mining, which is one of the vital signs selected for ONSR.

\section{Spatial Design}

A common sample unit has been defined to accommodate the field protocols for monitoring all vital signs. The common sample unit is defined as a "stretch" of contiguous river of some minimum and maximum length. The geomorphology of the waterways within ONSR and the resulting biological processes are scale-dependent; that is, the distances associated with pool-riffle sequences increase as river size and flow increase. A key characteristic of the overall monitoring design is that all aquatic studies should be capable of producing unbiased estimates that are applicable to the entire stretch. Although stretches must be long enough to accommodate sampling to produce unbiased estimates for all studies, they do not have to be the same length. Once defined, sample unit boundaries remain fixed, and are used by all studies conducted under the unified monitoring design.

Two categories of stretch sizes have been established. In tributaries and upper main stems, stretch lengths are 1 to $2 \mathrm{~km}$; in lower main stems, stretch lengths are 3 to $5 \mathrm{~km}$. Within categories, stretch length is not fixed, but varies depending on several factors. Stretches were broken at natural features, such as confluences and springs. They also were delimited based on Valley Segment Type (VST) information. The initial sample frame of stretches was developed through a collaborative agreement with the Missouri Resource Assessment Partnership (MORAP). Missouri Aquatic Gap datasets were used; these are the same datasets used by the Missouri Department of Natural Resources (DNR) and the Missouri Department of Conservation (MDC). MORAP used a subset of data from the 1:100,000 National Hydrography Dataset (NHD) developed by USGS and the U.S. Environmental Protection Agency (USEPA). The dataset includes arcs representing the centerlines of wide streams and the segments of single-line streams. Selected attributes of the segments were extracted from various NHD tables using an Arc/Info ${ }^{\circledR}$ [Environmental Systems 
Research Institute (ESRI), Redlands, Calif.] macro; the attributes were attached directly to the arc component on the arc segments. These stream segments were classified according to variables such as temperature, stream size, flow, geology, soil texture, relative gradient, valley wall interaction (a surrogate for potential bluff pool habitat), stream size discrepancy, and channel type. Thus, each stretch has associated with it characteristics based on geographic information system (GIS) data that could be used in statistical analyses as covariates or domains (that is, subpopulations of interest for which parameter estimates are desired). The dataset was restricted to those stream segments that touched the ONSR jurisdictional boundary or other adjacent public lands. The final sample frame was established by removing all stretches that were not entirely or partially within ONSR boundaries (the MORAP dataset included adjacent public lands). All secondary channels, which occur where a waterway splits and flows around an island, were then removed because they transport the smaller volume of water.

\section{Selecting the Stretches to be Sampled}

Spatial balance is important because all responses are known to be spatially autocorrelated (that is, units close to one another tend to respond similarly). When responses are correlated in space, spatial balance can greatly improve the precision of the resulting estimates. The Generalized Random Tessellation Stratified (GRTS) method of sample selection (Stevens and Olsen, 1999, 2004) was employed to achieve spatial balance. The GRTS technique, which generates a random sample that is spatially balanced, allows multiple studies to maximize overlap of selected streams by utilizing a common sample. It also allows units to be added without bias after an initial sample has been drawn. Additionally, because GRTS samples are not evenly spaced, sample locations are not in phase with a longitudinally cyclic response. Perhaps the most desirable characteristic of GRTS is that for any sample size, any subset of stretches in the ordered GRTS sample constitutes a spatially balanced sample. This characteristic is desirable because it allows multiple studies to maximize overlap and add stretches in a way that guarantees spatial balance.

The GRTS samples were drawn with the S-Draw program (Western Ecosystem Technologies, Inc., 2008), with the main stem sites weighted by stretch length. The S-Draw program allows for several options in drawing the sample. The hierarchical structure was randomized (Stevens and Olsen, 1999). The reverse hierarchical ordering option, which assures that any contiguous set of stretches will be spatially balanced, was used (Stevens and Olsen, 2004) with a random number seed generated from the system clock (the default option).

All GRTS draws were "oversampled" (that is, more sites were selected and ordered than will be immediately sampled). This allows for an increase in the number of sites in the future (if budget allows) without decreasing the overall degree of spatial balance. Oversampling also provides the flexibility not to sample certain sites. In such a situation, sampling can progress to the next site in the ordered GRTS list while sacrificing only a small degree of spatial balance.

A greater degree of control was desired for the main stem than was possible by selecting all stretches from the same pool with GRTS (which has a strong random element). The Jacks Fork, Upper Current River, and Lower Current River (upstream and downstream, respectively, of the confluence with the Jacks Fork) differ profoundly, primarily due to the influence of large springs. A total of 130 stretches comprised the sample frame for these main stems. Stretches on the Jacks Fork $(n=39)$ and Upper Current River $(n=53)$ are approximately 1 to $2 \mathrm{~km}$ long. Stretches on the Lower Current River upstream from Van Buren (where a break in the ONSR boundary occurs) were approximately 1 to $2 \mathrm{~km}$ long, and stretches below Van Buren were approximately 3 to $5 \mathrm{~km}$ long. The Current River below Van Buren has greater flows, in large part because of the input of Big Spring [12.2 cubic meters per second $\left.\left(\mathrm{m}^{3} / \mathrm{s}\right)\right]$. A total of 38 stretches were identified on the Lower Current River. An equal number of sample sites on each of these three main stem sections was desired. Thus, the main stems within ONSR were divided into three groups [Jacks Fork, Upper Current River (above confluence with the Jacks Fork), and Lower Current River (below the Jacks Fork)] before the GRTS sample was selected. Following these criteria, GRTS was used to order 64 main stem stretches within ONSR. Although immediate sampling is planned only for the first nine stretches (fig. 1, table 1), this procedure will allow an increase in the number of stretches sampled in the future or integration with other studies with a larger sample size without sacrificing spatial balance.

The total number of stretches to be sampled annually in the unified monitoring design is limited primarily by budget and personnel. Taking into account the other HTLN protocols that will be implemented at ONSR, it was determined that 12 total stretches could be sampled (nine main stem stretches and three tributary stretches). However, metals monitoring will focus on the nine main stem stretches, with the addition of the downstream-most non-floodplain stretch of Blair Creek, a tributary of the Current River (fig. 1, table 1). There is substantial interest in Blair Creek because of its proximity to active mining in the New Lead Belt.

\section{Temporal Design}

All nine main stem stretches and Blair Creek will be sampled at least once every 5 years. There are presently (2008) no mining activities in any ONSR surface watersheds; however, in the event that mining activity expands, the sampling frequency can be increased.

\section{Monitoring Organism Selection}

Metal concentrations can be monitored in samples representing virtually all living and non-living components of aquatic ecosystems (water, sediment, plants, and animals). 


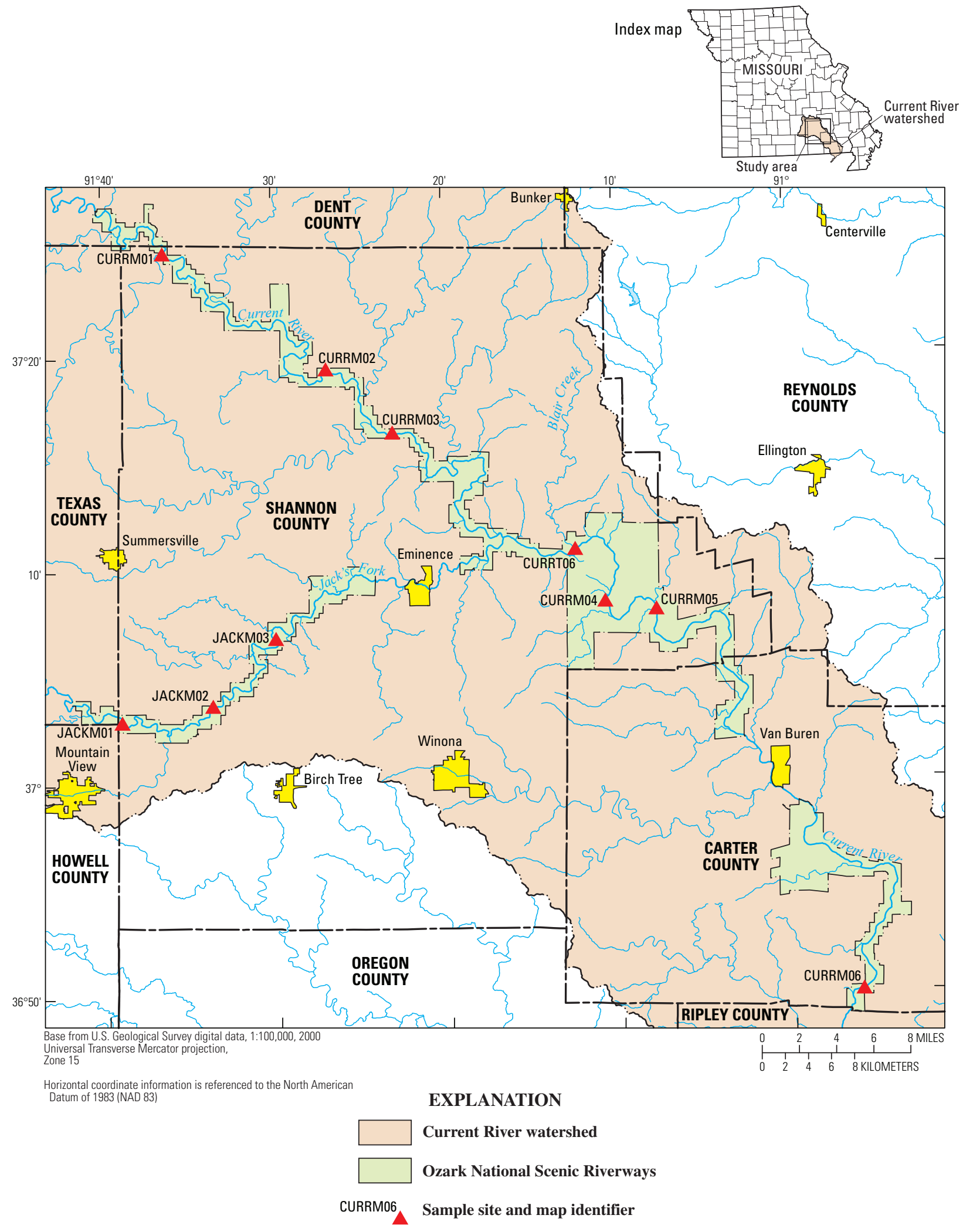

Figure 1. Ozark National Scenic Riverways (ONSR). 
Table 1. Reaches and stretches selected for monitoring.

[Easting and northing; Universal Transverse Mercator Projection, NAD83, Zone 15N]

\begin{tabular}{|c|c|c|c|c|c|c|c|c|c|}
\hline $\begin{array}{l}\text { Reach ID } \\
\text { (fig. 1) }\end{array}$ & $\begin{array}{l}\text { River } \\
\text { basin }\end{array}$ & Site type & $\begin{array}{c}\text { Site } \\
\text { number }\end{array}$ & County & $\begin{array}{l}\text { Stretch } \\
\text { ID }\end{array}$ & $\begin{array}{l}\text { Lower } \\
\text { stretch } \\
\text { easting }\end{array}$ & $\begin{array}{c}\text { Lower } \\
\text { stretch } \\
\text { northing }\end{array}$ & $\begin{array}{l}\text { Lower } \\
\text { reach } \\
\text { easting }\end{array}$ & $\begin{array}{c}\text { Lower reach } \\
\text { northing }\end{array}$ \\
\hline CURRM02 & Current & Main stem & 02 & Shannon & 35 & 637468.41 & 4131822.17 & 637113.180 & 4131465.688 \\
\hline CURRM04 & Current & Main stem & 04 & Shannon & 67 & 661785.40 & 4111783.86 & 662104.165 & 4112724.645 \\
\hline CURRM05 & Current & Main stem & 05 & Shannon & 71 & 666195.85 & 4111128.94 & 666087.431 & 4111411.528 \\
\hline CURRM06 & Current & Main stem & 06 & Carter & 97 & 684220.63 & 4078321.12 & 685209.621 & 4079792.188 \\
\hline JACKM03 & Jacks Fork & Main stem & 03 & Shannon & 123 & 633244.58 & 4108431.69 & 633452.088 & 4108220.025 \\
\hline CURRT06 & Current & Tributary (Blair Creek) & 06 & Shannon & 917 & 659132.19 & 4116340.75 & 659132.190 & 4116340.750 \\
\hline
\end{tabular}

Each sample type has advantages and disadvantages that differ among the parameters (in this example, metals) to be monitored. General criteria for selecting a sample type or types include spatial and temporal variability, analytical detection thresholds, costs, and the degree to which concentrations in a given matrix represent "environmental conditions," including site fidelity - the extent to which an organism represents the location from which it was collected. Effects of contaminant exposure at many levels of biological organization (biochemical, organ, organism, population, and community) also can be monitored; however, except for certain specific biochemical responses (Schmitt and others, 1984, 2007c), most effects are not contaminant-specific and can be affected by many factors in addition to chemical exposure.

Crawford and Luoma (1993) completed an extensive literature review pertaining to organic and inorganic contaminant monitoring in biota as part of the USGS National Water-Quality Assessment Program (NAWQA) development (Hirsch and others, 1988). The following criteria were identified for choosing species for chemical analysis: Chemical concentrations in the organisms should be responsive to environmental exposure; uptake of contaminants by organisms should be rapid; concentrations in the organisms should be greater than those in water; the organisms must not be killed by exposure to low levels of the contaminants to be monitored; concentrations in organisms should vary little within a site; the organisms should be relatively sedentary so as to reflect concentrations in the collection locale; the organisms should be abundant and widespread in the study area to facilitate comparisons; the organisms should be sufficiently large, abundant, or both to provide adequate tissue for analysis; the organisms should be sufficiently long-lived to integrate exposure concentrations over at least several months; and the organisms should be easy to sample (Crawford and Luoma, 1993). An additional consideration of the NPS is to minimize the removal of aquatic organisms, especially those considered to be rare, recreationally significant, or ecologically significant.

A problem shared by all programs and protocols relying on the collection of indigenous organisms is that there are no truly ubiquitous large, long-lived, abundant, and sedentary species that accumulate all contaminants equally well. Of the organisms available for consideration in ONSR, certain invertebrates meet most requirements for trace-metal monitoring. Most aquatic macroinvertebrates are comparatively sedentary, and generally they do not regulate metals as well as fish. Many invertebrates also ingest varying amounts of particulate material (and its contaminants) from the water column, bed sediment, or both depending on feeding guild (Goodyear and McNeill, 1999). Consequently, metals concentrations in invertebrates tend to reflect environmental concentrations comparatively well (Crawford and Luoma, 1993; Goodyear and McNeill, 1999). The NAWQA program considered sampling fish, invertebrates (mollusks, crayfish, aquatic insect larvae), and plants (attached algae, macroalgae, macrophytes), and ultimately adopted a step-down approach for trace metals depending on taxa available at a site. Organisms are sampled by NAWQA in the following order of preference: Asian clams (Corbicula fluminea), aquatic insects, target fish species (as identified by Crawford and Luoma, 1993), and aquatic plants. In the Ozark Plateaus Study Unit (Petersen and others, 1998), 
which included waters of the ONSR, Asian clams were collected and analyzed by NAWQA where the species could be found. Liver tissue from several fish species (Crawford and Luoma, 1993) were sampled elsewhere; samples were obtained preferentially from longear sunfish (Lepomis megalotis) and, secondarily, from smallmouth bass (Micropterus dolomieu). Crayfish met all the monitoring criteria identified by NAWQA, but they were not selected because information was not available on the uptake and retention of organic chemicals by these organisms (Crawford and Luoma, 1993). Although organic chemicals remain a priority for NAWQA, they are not presently (2008) an issue in ONSR. Based on a discussion of these factors with NPS personnel, crayfish and Asian clams were selected for monitoring at ONSR. Attributes of these organisms for metals monitoring are summarized in the following sections.

\section{Crayfish}

Crayfish constitute a large percentage of the invertebrate biomass in Ozark streams (Hobbs, 1993; Momot, 1995; Rabeni and others, 1995; Whitledge and Rabeni, 1997; DiStefano, 2005). They are considered "ecological dominants" (Simberloff, 1998) that shape the entire aquatic community. Crayfish are opportunistic omnivores that feed on varying proportions of fish, aquatic invertebrates, periphyton, and detritus during their life cycle (Hobbs, 1993; Momot, 1995; Whitledge and Rabeni, 1997; Parkyn and others, 2001). Crayfish process large quantities of organic material (including macrophytes, attached algae, and detritus) and represent a significant food source for smallmouth bass, other fishes, and riparian wildlife (Probst and others, 1984; Whitledge and Rabeni, 1997; DiStefano, 2005). Crayfish tend to accumulate non-essential metals such as lead and cadmium in proportion to exposure, but may be able to regulate copper and zinc (Gillespie and others, 1977; Dickson and others, 1979; Knowlton and others, 1983; Crawford and Luoma, 1993; Schmitt and others, 2007b). Lead concentrations in crayfish from mining-affected streams in southeast Missouri were well correlated with those in sediments, but were lower by a factor of about five (Schmitt and Finger, 1982). Most metals in crayfish concentrate in the hepatopancreas, antennal (green) gland, exoskeleton, and digestive tract (Dickson and others, 1979; Roldan and Shivers, 1987; Crawford and Luoma, 1993); however, mercury also accumulates in muscle (Allard and Stokes, 1989). The NAWQA program considered dissecting the hepatopancreas from crayfish for analysis (Crawford and Luoma, 1993); however, metals in whole crayfish (including the contents of the digestive tract) represent the concentrations to which higherlevel organisms are exposed (Schmitt and others, 2006). In addition, there is a large body of extant data describing metals concentrations in whole crayfish from streams representing the range of metals concentrations present in Missouri to which concentrations in ONSR crayfish can be compared (Wixson, 1978; Schmitt and Finger, 1982; Whelan, 1983; Allen and Wilson, 1992; Wildhaber and others, 1997; Besser and others, 2007a; Allert and others, 2008). There also are uptake data from locally relevant controlled studies (Knowlton and others, 1983; Besser and Rabeni, 1987), and the analysis of metals in crayfish represents an important component of ongoing USGS studies related to lead-zinc mining in southern Missouri (Imes, 2002; Besser and others, 2007a; Allert and others, 2008).

Riffle-dwelling crayfish of the genus Orconectes, which are distributed across the Ozark Plateau, were targeted for monitoring. The golden crayfish (O. luteus) is widespread in the Ozarks (Pflieger, 1996) and is the prevalent species at ONSR (Rabeni and others, 1995). Consequently, and even though it does not grow as large as some other species, $O$. luteus is the preferred species. The spothanded crayfish (O. punctimanus) is the primary alternate species in the event that golden crayfish are not available at a site, followed by the Ozark crayfish (O. Ozarkae) and Hubbs' crayfish (Cambarus hubbsi).

Crayfish molt several times during the growing season, which may affect metals concentrations; however, reported effects of size on metals concentrations vary. For example, Knowlton and others (1983) indicated that lead concentrations decreased with size, but Dickson and others (1979) reported no size-related concentration effects for metals. Samples should nevertheless be collected as consistently as possible with respect to sampling period and crayfish size.

\section{Asian Clam}

The Asian clam is an exotic species that has become established throughout much of North America. It is extremely invasive and is regarded as a threat to indigenous mussels and other native aquatic organisms (McMahon, 1983; Oesch, 1995). In 1992, when NAWQA sampled the Current River and Jacks Fork for contaminants in biota, Asian clams were obtained only at the downstream-most site on the Current River at Van Buren (Petersen and others, 1998). This species has since been found throughout most of the Current River and Jacks Fork within ONSR (Schmitt and others, 2007b).

The use of the Asian clam for contaminants monitoring has grown in popularity as the species has spread. As a result, and as noted by Crawford and Luoma (1993), protocols for monitoring with Asian clams are well documented (Graney and others, 1983; Foe and Knight, 1987; Leland and Scudder, 1990). Asian clams accumulate most metals in proportion to exposure, with the possible exception of zinc (Crawford and Luoma, 1993). Laboratory exposure studies indicate a concentration-dependent linear uptake of mercury and cadmium, but with a plateau effect for cadmium, and that concentrations persist for at least 30 days post-exposure (Inza and others, 1998). Studies with caged, transplanted Asian clams indicate that tissue concentrations may not reflect zinc gradients in water or sediment as well as those of cadmium (Baudrimont and others, 1999). Schmitt and others (2007b) reported that cobalt concentrations in Asian clams at sites within and outside ONSR were relatively uniform, indicating that internal concentrations may be regulated; however, zinc concentrations in Asian clams 
differed. Data from mining-affected parts of the Spring River Basin (Missouri, Kansas, and Oklahoma) indicate that concentrations of lead, cadmium, and zinc in wild Asian clams are correlated with concentrations in sediment (Angelo and others, 2007). Concentrations of cadmium, but not of lead or zinc, also increase with an increase of shell diameter (Angelo and others, 2007). Consequently, and as described for crayfish, the collection of similar sized Asian clams should be the objective.

Protocols for metals monitoring with Asian clams vary with respect to the incorporation of a depuration period. The NAWQA program incorporated a 24-hour depuration period; however, concentrations of lead, but not cadmium or zinc, may decline after depuration for 24 hours because of the preferential binding of lead to sediment particles (Angelo and others, 2007). Nevertheless, a depuration period is included in the protocol for ONSR for consistency with previous studies, with the recognition that it probably reduces the original lead concentration.

\section{Methods}

\section{Field Season and Sampling Preparations}

A list of field equipment and supplies is provided in SOP 1; data forms (appendix 1) and sample labels (appendix 2) can be found at the back of this report. Extreme care must be exercised to avoid external contamination, including cross-contamination between samples, when sampling for trace metals (Schmitt and Finger, 1987). Sampling equipment and containers must be thoroughly cleaned between samples and sites and stored in plastic bags, and personnel handling samples will wear disposable gloves. Work surfaces must be covered with disposable material (paper or polyethylene) that is cleaned or replaced between samples, and should be used only at one site if samples from multiple sites will be processed. Because pre-cleaning containers requires acid solutions and ultra-pure water that are generally not available to NPS personnel, the protocol maximizes the use of commercially available pre-cleaned containers and disposable items that do not have to be acid-cleaned.

Preventing the introduction of invasive species and mitigating against the further spread of those already present at ONSR is a tacit objective of this and other NPS monitoring protocols. The Asian clam is present at ONSR, but other aquatic nuisance species such as the zebra mussel (Dreissena polymorpha) and didymo algae (Didymosphenia geminate) are not; however, both species are present in northern Arkansas, and zebra mussels are present elsewhere in Missouri. To prevent their introduction, all equipment, containers, boots, and personal flotation devices (PFDs) used for sampling at ONSR should be labeled as such and not used elsewhere, and should be thoroughly cleaned and air-dried for at least 48 hours between uses.
The preferred collection period is September, but sampling during August or October is acceptable (see SOP 2). Weekday sampling is preferable to weekends, to minimize contact with and interference from ONSR visitors. For safety reasons, a two-person team is recommended for aquatic field collections. Correctly sized PFDs are required for all personnel working in or near water regardless of season. Personnel that will collect crayfish and Asian clams should be able to identify them to species in the field and be familiar with the procedures described here and in the related SOPs. A resume of all personnel involved in the study should be on file at the HTLN office along with documentation that these individuals have been trained in all pertinent procedures. The movement of samples also should be documented; an example chain-ofcustody record, which accompanies samples as they change hands, is given in appendix 3 (at the back of this report).

Depending on the personnel involved and collection locations, scientific collection permits from MDC, the NPS, or both may also be required. Collections in MDC Natural Areas adjacent to ONSR (such as Blue Spring) may also require special permission. Applications for these permits must be submitted early in the sampling year to ensure approval, and both permits require an annual report. The address for obtaining MDC permits is given in SOP 1. Under an MDC permit, the Conservation Agent in the county of collection must also be notified in advance, and the permittee must be present during the collections.

\section{Field Methods}

For each selected stretch, three consecutive riffles will be chosen to represent a sample reach at the time of collection. Riffle selection is determined before sampling; the three riffles should be those located in consecutive order upstream from the first riffle above the lower geographic boundary of the selected stretch. Sampling procedures are described in more detail in SOP 2. Sample storage and shipment and other procedures to be followed upon completion of sampling are described in SOP 3.

\section{Crayfish}

Crayfish are captured by kick-seining or kick-netting in riffles containing coarse substrate or along the margins of emergent vegetation beds. They are removed from the nets and held alive in lined plastic buckets containing ambient water. Crayfish of 18 to 25 millimeters ( $\mathrm{mm}$ ) carapace length, which are typically young-of-the-year, are preferred. Crayfish of this size were present at all ONSR sites sampled in 2005 (Schmitt and others, 2007b). When at least 10 crayfish of the appropriate size have been collected from each riffle, they are transported to shore where the identification (species) of each animal is confirmed and it is measured (carapace length, in $\mathrm{mm}$ ).

Following identification and measurement, each individual crayfish is then carefully washed with ambient water and 
the combined sample of 10 specimens is either double-bagged in zip-seal plastic freezer bags or placed in pre-cleaned, prelabeled polyethylene jars. Crayfish that are not the preferred species or size are released and more are collected until the three samples are completed. Samples may be either chilled (on ice) or frozen (in dry ice) in the field, then transferred to a freezer $\left[-20^{\circ} \mathrm{C}\right.$ (degrees $\left.\left.\mathrm{C}\right)\right]$ upon return to the duty station. They are kept frozen until sent to the analytical laboratory, and then shipped frozen (in dry ice). The crayfish samples will be freeze-dried, homogenized, and analyzed for metals; moisture content (percent) may or may not be determined and reported. Concentrations are reported as micrograms per gram $(\mu \mathrm{g} / \mathrm{g})$ dry-weight (see section on Chemical Analysis and Quality Control later in this report).

\section{Asian clams}

Asian clams usually are harvested by gloved hand or with dip nets. They may be difficult to locate; during pilot studies, Asian clams were found along sandy margins or in sandy interstices among cobble. Three composite samples of nominally 10 animals each are collected for analysis, with 10 specimens coming from each of the three riffles described previously. The preferred size range based on the extant literature is 15 to $25 \mathrm{~mm}$ shell width; Asian clams obtained from ONSR sites in 2005 by Schmitt and others (2007b) were 15.5 to $21.4 \mathrm{~mm}$. As described for crayfish, Asian clams are held in lined plastic buckets containing ambient water until at least 10 specimens of the preferred size have been obtained from each riffle. They are transferred to shore where as much external material (sediment, algae) as possible is removed by hand from the external surfaces of the shell, the identity is confirmed, and the specimen is measured. Maximum shell diameter is recorded for each clam in each sample, and the specimens are transferred to a new, pre-labeled polyethylene bag about one third full of ambient water. The bag is then filled with oxygen, sealed, and placed in another bag containing a sample label; a sheet of sample labels is appended to the back of this report (appendix 2). Remaining specimens are released. The labeled, double-bagged sample is transferred to a cooler containing ambient water, and the process is repeated until three samples of 10 specimens have been obtained. The Asian clam samples remain in the bags of ambient water in the coolers for 24 hours, which allows them to depurate (that is, purge themselves of particulate material).

Following depuration, the samples either are doublebagged in zip-seal freezer bags or transferred to pre-labeled, pre-cleaned polyethylene jars and frozen and shipped as described for crayfish. In the laboratory, the soft tissues are separated from the shells, freeze-dried, and analyzed for trace metals. Metals concentrations are reported as $\mu \mathrm{g} / \mathrm{g}$ dry-weight. Moisture content (percent) may or may not be determined and reported (see section on Chemical Analysis and Quality Control later in this report).

\section{Alternate Species}

The collection of the target species is desirable, but not always possible, and alternate species can be substituted. Presently there is no alternate for Asian clam; lacking this species, no sample will be collected. If the full complement of golden crayfish or spothanded crayfish are not available at a site, other crayfish (Ozark crayfish, Hubbs crayfish) may be substituted; however, under no circumstance should a composite sample contain more than one species.

\section{Chemical Analysis and Laboratory Quality Control}

\section{Overview}

The Asian clam and crayfish samples from ONSR will be analyzed for lead, cadmium, cobalt, zinc, and nickel by inductively-coupled plasma mass spectrometry (ICP-MS), the most sensitive multi-elemental method currently available to most laboratories. High sensitivity is necessary because concentrations are expected to be low based on samples obtained in 2005 (Schmitt and others, 2007b). Statistical analysis and trend detection based on censored values [that is, less than the method detection limits (MDLs)] are inherently difficult (Bauch and others, 2005), a problem that is exacerbated when detection limits change with time. Censored values greater than toxicity thresholds also are inherently problematic Accordingly, target MDLs are $0.05 \mu \mathrm{g} / \mathrm{g}$ dry weight (approximately $0.01 \mu \mathrm{g} / \mathrm{g}$ wet weight) for cadmium, cobalt, nickel, and lead; and $1.0 \mu \mathrm{g} / \mathrm{g}$ dry weight $(0.2 \mu \mathrm{g} / \mathrm{g}$ wet weight $)$ for zinc. These can be achieved by ICP-MS.

Chemical analyses generally should follow Crawford and Luoma (1993), May and others (1997), Brumbaugh and others (2005), Besser and others (2007a), and Schmitt and others (2007b). Composite samples of whole crayfish (with intact exoskeletons and digestive tracts) are prepared for analysis by lyophilization followed by homogenization to a powder with a cryogenic mill. Asian clams are lyophilized whole and the soft tissues subsequently separated from the shells. The soft tissues of all the clams or crayfish in the composite sample are homogenized to a coarse powder by pulverizing them with a glass rod. Alternately, if enough mass is available, clam tissue is processed with a cryo mill in the same manner as whole crayfish. Dried, homogenized samples are digested in nitric acid and hydrogen peroxide in a laboratory microwave oven, and the digestates are analyzed for lead, cadmium, cobalt, zinc, and nickel by ICP-MS (Brumbaugh and others, 2005; Besser and others, 2007a).

The chemical analyses can be performed by government, university, or private (contract) laboratories. Regardless of the laboratory performing the analyses, the analytical plan should incorporate field and laboratory replication, procedural blanks, fortified samples (spikes), and standard reference materials. The data should be examined for repeatability 
(mean, minimum, and maximum percent deviation of replicates), blank contamination, recovery efficiency (from spikes), and conformance with certified concentrations in reference materials. Samples analyzed with associated quality control (QC) checks that fail to meet acceptance criteria should be reanalyzed or, in some instances "flagged" - that is, identified as having failed one or more QC parameters. Flagged values may be used, but may be eliminated from consideration when the data are reviewed, interpreted, and reported. Analytical laboratories routinely analyze blanks, standards, and duplicates to meet their needs, but not necessarily in the number necessary for the monitoring program; however, the cost of analyzing field replicates and any additional QC beyond that normally performed will have to be budgeted.

The field and laboratory procedures described in this document and its associated SOPs conform to USEPA Good Laboratory Practices (USEPA, 1989) and are in general accordance with USEPA Contract Laboratory Program guidelines (USEPA, 2004). If implemented as described, these procedures will yield defensible data suitable for monitoring and information purposes; however, these data may not be entirely adequate to support regulatory procedures or litigation, which generally require the development of and documented conformance with a Quality Assurance (QA) Plan. General guidelines for analytical QC are summarized in the following section.

\section{General Analytical Quality Control}

Quality-control measures incorporated at the digestion stage of the analyses should include digestion blanks, certified reference materials, replicates, and pre-digestion fortified samples (spikes). A calibration blank and an independent calibration verification standard should be analyzed regularly to confirm the calibration status of the ICP-MS throughout the instrumental analyses. As a check for potential interferences, post-digestion spikes should be performed, and dilution percent differences based on five-fold dilutions of the sample digestates should be determined. Instrument detection limits (IDLs), MDLs, and method quantitation limits (MQLs) should be estimated for each element in each type of sample based on the standard deviations of the measured concentrations in the blanks, which should be computed according to standard published methods (USEPA, 2004). Instrumental precision should be determined as the relative percent difference between duplicate analyses of digestates.

\section{Instrument Calibration and Calibration Verification}

At least three standard concentrations and a calibration blank should be used for instrument calibration; the coefficient of determination $\left(\mathrm{r}^{2}\right)$ of the regression for each group of measurements should be at least 0.995 . A calibration verification solution should be prepared to a mid-range concentration from an independent stock source and be measured after every 10 sample analyses. The measured value for this solution should be within 10 percent of the expected value. If these criteria are not met, the check solution should be re-analyzed. If it still fails, the instrument calibration should be repeated, and any samples analyzed after the previous acceptable calibration verification should be re-analyzed. If recalibration fails to correct the discrepancy, new standards should be prepared, and the samples should be re-analyzed.

\section{Blanks and Blank Verification}

Procedural blanks (preferably three per preparation set) should be analyzed to provide measurements needed for determining the MDL. Blank equivalent concentrations (BECs) should be no more than 10 times the average of the three most recently determined IDLs. Re-preparation of all samples in non-conforming preparation sets is preferable to flagging; however, flagging may be acceptable under some circumstances depending on the concentration of the analyte the relative percent error estimated for blank equivalent concentrations (BECs). If the BECs exceed the previously stated criteria but all sample concentrations are at least 10 times greater than the greatest BEC, then flagging may be acceptable. If all sample concentrations are at least 20 times greater than the greatest BEC, no corrective action usually is required.

\section{Detection Limits}

The IDLs and MDLs should be determined periodically according to USEPA or other standard, published methods. The IDLs should be determined every 6 months. The MDLs should be determined for each sample preparation set. In the event that a measured MDL fails to meet a target, the analyses required for the MDL determination should be repeated. If the MDL still fails to meet the criteria, the reason should be determined (for example, procedural contamination or poor instrument performance) and corrected. If necessary, the samples should be re-prepared, re-analyzed, or both.

\section{Post-Digestion Spikes}

At least one post-digestion spike should be analyzed for every 20 samples of each sample type (Asian clam, crayfish) to check for sample matrix effects. For each metal in each sample type, a suggested target for average recovery of postdigestion spikes is 100 percent \pm (plus-or-minus) 10 percent, with no individual recovery exceeding \pm 20 percent. If upon re-analysis an individual spike fails to meet the latter criterion, or if the average recovery criteria are not met, all samples of a similar type should be analyzed by the method of standard additions. Alternatively, those results should be flagged.

\section{Standard Additions}

Samples for which conventional calibration procedures yield unsatisfactory QC results may be re-analyzed by the method of standard additions. A blank (" 0 -X") and spikes of " $0.5-X$ " and " $1-X$," where " $X$ " is approximately the low-end instrument calibration concentration, will be analyzed. The 
$r^{2}$ for each regression should be at least 0.995 , otherwise the sample should be re-analyzed. If the calculated sample concentration is more than twice $\mathrm{X}$, it should be diluted as necessary and re-analyzed. A calibration verification solution also should be analyzed by this method; the result should be within +10 percent of the true value.

\section{Method Precision}

An estimate of method precision should be determined either from at least one triplicate (preferred) or duplicate preparation (digestion and analysis) per 20 samples of each sample type. Computation of the percent relative standard deviation (percent RSD) or the relative percent difference (RPD) should then be evaluated. Typical targets for biological tissue for the mean percent RSD or RPD are \pm 20 percent; however, these targets are valid only for the estimation of methods precision if the concentration in the replicated sample exceeds the MDL by at least 10 -fold. To evaluate instrument precision, at least one sample digestate solution should be prepared for duplicate analysis for every 20 samples of each type. Reproducibility of duplicate readings should be within \pm 10 percent except at concentrations that are $\leq$ (less than or equal to) 20 -fold greater than the IDL, which can be greater. Groups of samples for which these criteria are exceeded should be re-analyzed; if they fail a second time, they should be flagged.

\section{Standard Reference Materials}

At least one representative reference tissue should be prepared for each type of sample. Appropriate reference materials for crayfish and Asian clams include National Institute of Standards and Technology (NIST) oyster (NIST 1566a, 1566b) and National Research Council Canada (NRCC) lobster hepatopancreas (NRCC TORT-1). For each measured result, the suggested target criterion is the certified range (usually represented by the $95 \%$ confidence interval about the mean) extended by \pm 10 percent of the certified mean. This approach provides an allowance for measurements of certified reference materials for which the certified 95 percent confidence limits are unusually narrow. In addition, these criteria should only be applied if the concentration of the analyte in the reference material is at least 10 -fold greater than the target MDL.

\section{Pre-Digestion Spikes}

At least two pre-digestion spikes for each analyte should be prepared for every 20 samples of each type. The target for mean recovery of pre-digestion spikes is $100 \pm 20$ percent with not more than 20 percent of individual spike recoveries exceeding \pm 50 percent error; however, the second criterion does not apply if effective concentration in the spike is not at least 50 percent of the concentration measured in the un-spiked sample. Spiked samples meeting this condition but failing the acceptance criteria should be flagged. If more than one analyte spike recovery result per preparation set fails the second criterion, then all samples in the preparation set should be re-digested and re-analyzed. Alternatively, all results in the digestion set should be flagged for the suspect analyte(s).

\section{Instrumental Precision}

At least one sample digestate solution should be prepared for duplicate analysis for every 20 samples of each type. Reproducibility of duplicate readings should be within \pm 10 percent except at concentrations that are $\leq 20$-fold greater than the IDL. For concentrations between 10- and 20-fold greater than the IDL, agreement should be within \pm 20 percent. No criteria are suggested for values less than 10 times the IDL. A duplicate analysis producing variation outside these criteria should be re-run. If the result is still outside the criteria, all samples in the group should be flagged.

\section{Background and Spectral Interference Check}

Spectral interferences from representative samples of each type should be checked by one or more of three following methods: (a) analysis at a secondary mass; (b) re-analysis after dilution by at least five-fold; and (c) for determinations having known interferences, a check solution containing the analyte and interfering element(s) can be analyzed. Results for (a), (b), or (c) with the original analysis should be within 10 percent of the alternate, undiluted, or true value. If not, troubleshooting and elimination of the interference must be documented or an alternate method of analysis performed; otherwise, all samples in the group should be flagged.

\section{Procedural Errors and Deviations}

Procedural errors occasionally may occur during sample preparation or analysis. In these instances, any corrective actions should be documented. The corrective action employed depends upon the stage at which the suspicion arose. Procedural errors arising at the chemical preparation stage, such as accidental sample spilling or dropping, digestion losses, incorrect spiking or dilution, or possible mislabeling should be documented. Corrective action might include continuation of process with sample flagging or complete repreparation.

Procedural errors at the instrumental analysis stage can be indicated by a variety of reasons including unusually large variations between duplicate analyses, off-scale concentrations, and unusual concentration compared to other samples. The corrective action for re-analysis at this stage should include written documentation of the reason or reasons for rejecting the original analysis. All re-analyses should be identified as such.

\section{Analytical Data Review and Completeness}

Data related to sample processing and analysis should be reviewed, approved, and retained at the laboratory. Any errors that are discovered should be rectified and documented during the review process. Corrections should become part of the permanent records associated with the samples. At least 
95 percent completeness (percent of analytical results reported without flags) should be obtainable.

\section{Data Management}

\section{Overview of Database Design}

All data management activities related to this protocol are described in SOP 5. Microsoft Access 2003 is the primary software for managing ONSR elemental contaminants data. ESRI ArcInfo 9 serves as a tool for validation of spatial data residing in Access 2003. Data products are posted at the NPS Inventory and Monitoring (I\&M) website (http://science. nature.nps. gov/nrdata). Metadata for ONSR elemental contaminants monitoring are available on the NPS I\&M application server http://science.nature.nps.gov/im/monitor protocoldb.cfm). The data management activities described in this document are based on the recommendations of Rowell and others (2005) and the NPS I\&M Program (http://science. nature.nps.gov/im/monitor).

The general data model for ONSR elemental contaminants monitoring consists of two core sets of tables. One set manages species data (Asian clam shell diameters and crayfish carapace lengths) and the other associated dry-weight concentrations of specific metals. These data are linked in time and space by way of standardized event and location tables that provide detailed information associated with each sampling point and time. Supporting tables include species attributes, observers, and administrative information; look-up tables are linked to relevant tables to provide the values for pick-lists on data-entry forms, thereby reducing possible error during data entry (see Data Verification and Editing, later in this report).

\section{Data Entry}

Several features have been designed into the database to minimize errors that occur when field data are transcribed to the database for storage and analysis. Forms are used as portals for data entry into the database. Standardized identifiers (such as sample location and event) are selected from a list of easily interpreted codes. Species measurement data are entered into fields linked to appropriate tables. Look-up tables contain project-specific data and prohibit entry of data into a field if a corresponding value is not included in the look-up table. Consequently, only valid names or measures may be entered and spelling mistakes are eliminated. Species measures are selected using a pick list or by typing the beginning of the name.

\section{Data Verification and Editing}

Data verification immediately follows data entry, and involves checking the accuracy of computerized records against the original source, usually paper field records. Although the goal of data entry is to achieve
100 percent correct entries, this rarely is accomplished. To minimize transcription errors, NPS policy is to verify 100 percent of records to their original source by staff familiar with project design and field implementation. Further, 10 percent of records are reviewed a second time by the Project Manager and the results of that comparison reported with the data. If errors are found in the Project Manager's review, then the entire data set is verified again. Once the computerized data are verified as accurately reflecting the original field data, the paper forms are archived and the electronic version is used for all subsequent data activities.

Although data may be transcribed correctly from the original field forms, they may not be accurate or logical. For example, an Asian clam shell measurement of $333 \mathrm{~mm}$ instead of $33 \mathrm{~mm}$ may be illogical and almost certainly incorrect, whether or not it was properly transcribed from field forms. The process of reviewing computerized data for range and logic errors is the validation stage. Certain components of data validation are built into data entry forms (for example, range limits). Data validation also can be extended into the design and structure of the database. As much as possible, values for data-entry forms have been limited to valid entries stored in the look-up tables.

Additional data validation can be accomplished during verification if the operator is sufficiently knowledgeable about the data. The project manager will validate the data after verification is complete. Validation procedures seek to identify generic errors (such as missing, mismatched, or duplicate records) as well as errors specific to particular projects. For example, one database query detects ambiguous records with a location ID and an event ID; another counts the number of observations sampled per site to be sure all data were collected and entered.

During the entry, verification, and validation phases, the project manager is responsible for the data. The project manager must assure consistency between field forms and the database by noting how and why any changes were made to the data on the original field forms. In general, changes made to the field forms should not be made via erasure, but rather through marginal notes or attached explanations. Once validation is complete, the data set is turned over to the data manager for archiving and storage.

Spatial validation of database sample coordinates can be accomplished using ArcGIS (ESRI, Inc.). Because this is an Access-maintained database, it can be integrated directly with ArcCatalog (ArcGIS, ESRI, Inc.) as an object linking and embedding database (OLE DB) object that allows part of an object (such as a database or spreadsheet) to be exported and then re-imported into a different object. Coordinate data [Universal Transverse Mercator (UTM) northing and easting] of the locations table can then be used to validate the UTM coordinate values for sample locations stored in Access against the original Global Positioning System (GPS) coordinates. 


\section{Metadata Procedures}

Biological and spatial metadata are developed in accordance with guidelines established in Rowell and others (2005) using the NPS Database Metadata Extractor (a Microsoft Access add-in), ESRI ArcCatalog, and the NPS Metadata Editor and Tools extension. Metadata follow the Federal Geographic Data Committee (FGDC) standards and include Integrated Taxonomic Information System (ITIS) biological profile elements that allow integration of the metadata record with the NPS I\&M NPSpecies and NatureBib online databases. Metadata are then parsed using a USGS metadata parser to check for errors.

\section{Database Versions}

Changes in database structure and functionality require a versioning system. This allows for the tracking of changes with time. With proper controls and communication, versioning ensures that only the most current version is used in any analysis. Versioning of archived data sets is handled by adding a two digit number separated by a period to the file name, with the first version being numbered XXXXXX1.0. Minor changes such as revisions in forms and report content should be noted by an increase of the number to the right of the period. Major changes such as migration between Access versions or database normalization across multiple tables should be indicated by an increase in the number to the left of the period. Frequent users of the data are notified of the updates, and provided with a copy of the most recent archived version.

\section{Database Security}

Secure data archiving is essential for protecting data files from corruption. No versions of the database should be deleted under any circumstance. Monitoring databases are small and do not require significant computer drive space or resources. On the other hand, they represent primary data and are expensive to create and impossible to replace. Multiple backup copies of all program data are maintained at the HTLN offices, at the Wilson's Creek National Battlefield in Republic, Missouri, and at the Missouri State University campus offices in Springfield. Tape backups of the databases are made weekly. Each weekly full backup copy is maintained at the Wilson's Creek National Battlefield. Once a month, one tape copy is stored offsite.

Data currently (2008) are available on request for research and management applications for database versions where all QA/QC has been completed and the data have been archived. Most data requests currently are met using file transfer protocol (FTP) services. Parts of the monitoring data collected under this protocol will be made available for download directly from the NPS I\&M Monitoring webpage. Information related to location and persistence of species determined to be threatened or endangered will not be made available for download by the general public. In addition, metadata will be available directly from the NPS I\&M NR-GIS Metadata and Data metadata server (http://science.nature.nps.gov/nrdata). Data requests should be directed to:

Data Manager

Wilson's Creek National Battlefield

6424 W. Farm Road 182

Republic, MO 65738-9514

(417) 732-6438

\section{Data Analysis and Interpretation}

One of the primary recommendations from a workshop on environmental monitoring organized by the Ecological Society of America was that trend studies should focus on description of trends and their uncertainty rather than on hypothesis testing (Olsen and others, 1997). Core data analyses and presentation methods are, therefore, focused on parameter estimates; they will provide a standard format for evaluation of all metals concentrations, are straightforward to interpret, and can quickly be updated whenever additional data become available. They will primarily consist of point estimates of metals concentrations and the associated uncertainties. In the 2005 ONSR pilot project, a sample size of three replicates per stretch resulted in relatively small amounts of variability among replicates (Schmitt and others, 2007b).

\section{Control Charts}

A control chart approach will be employed for long-term analyses. Control charts represent a basic summary of a data set that indicates which variables are in the greatest need of more in-depth analyses or management action. Developed for industrial applications, control charts indicate when a system is going "out of control" by plotting through time some measure of a stochastic process with reference to its expected value (Beauregard and others, 1992; Gyrna, 2001; Montgomery, 2001). Control charts have been applied to ecological data (McBean and Rovers, 1998; Manly, 2001), including fish communities (Petterson, 1998; Anderson and Thompson, 2004) and other natural resources (Atkinson and others, 2003). In this application, control charts will contain only upper control limits, which will specify toxicity thresholds for invertebrate metals concentrations that represent dietary risks of metals to riparian wildlife. Construction of the control chart and an example are presented in SOP 5.

The toxicity thresholds have been determined through food chain analysis using procedures developed for conducting ecological risk assessments (USEPA, 1992, 1997, 1999, 2007b). Cadmium, cobalt, nickel, lead, and zinc are natural constituents of the earth's crust. Although cobalt, nickel, and zinc are essential elements, these metals all are potentially toxic to wildlife at concentrations that can occur in the environment. Because of the extent of the river system at ONSR (the main stems of the Current River and Jacks Fork extend 
for more than $200 \mathrm{~km}$ within the ONSR boundaries), averaging over all stretches to obtain a single ONSR-wide estimate will not be attempted. No individual point estimate would be representative of most of the river(s). Such an approach would be problematic, especially if concentrations were low in most stretches but were high in a few. Thus, the primary focus will be on evaluating each stretch individually with time. This approach will allow evaluation of the potential effect of tributaries with confluences between sampled main stem stretches, and signal tributaries that require additional monitoring.

\section{Toxicity Threshold Development}

Risk analysis for warm-blooded vertebrates (homeotherms) is based on food chain analysis, the foundation of which is the toxicity reference value (TRV). The TRV is the daily contaminant intake rate in milligrams $(\mathrm{mg})$ of contaminant per kilogram $(\mathrm{kg})$ body weight per day associated with a toxicity threshold. The threshold can be either the no-observed-adverse-effect-level (NOAEL) or the lowest-observed-adverse-effect-level (LOAEL) for a specific contaminant in a relevant wildlife species as reported in the scientific literature. Toxicity reference values have been tabulated for a variety of birds and mammals (Sample and others, 1996; USEPA, 1993, 2005a, 2005b, 2005c, 2007a, 2007c). By definition, NOAEL-based TRVs are lower than LOAEL-based TRVs and are used for screening-level assessments, which are preliminary evaluations of ecological risk. NOAEL-based TRVs for wildlife recently (2007) have been approved by the USEPA as part of a process for establishing ecological soil screening levels (Eco-SSLs) for metals and other contaminants. The Eco-SSL TRVs for lead, zinc, cadmium, cobalt, and nickel are incorporated into the assessment described in SOP 5, which also contains a control chart example.

For analyses of homeotherms, receptor wildlife species are selected by the investigator to be representative of the ecosystem being modeled. Daily contaminant intake in each selected species is estimated and evaluated relative to the TRV. To estimate daily contaminant intake, the measured concentrations of the metal in the food source or sources being evaluated (crayfish and Asian clam, in units of $\mathrm{mg} / \mathrm{kg}$ wet-weight) is multiplied by the weight-normalized food ingestion rate ( $\mathrm{kg}$ food $/ \mathrm{kg}$ body weight/day) of the species. Weight-normalized food intake rates in homeotherms decrease with body weight; that is, small animals consume a greater proportion of their body weight per day than large animals (USEPA, 1993). With all other factors being equal, risk associated with dietary exposure to metals tends to be greatest in small mammals and birds. Weight-normalized food intake rates and body weights for wildlife as reported in the scientific literature also have been tabulated (Sample and others, 1996; USEPA, 1993).

Species bracketing the size range of birds and mammals likely to consume stream-dwelling aquatic invertebrates in southern Missouri were selected as receptors in ONSR. Great blue heron (Ardea herodias) and American mink (Mustela vison) were chosen as representative large, adult riparian birds and mammals, respectively. The American robin (Turdus migratorius) and short-tailed shrew (Blarina brevicauda) were selected to represent smaller birds and mammals. These small species are not riparian. They were selected based on body weight to represent organisms such as the least sandpiper (Calidris minutilla), spotted sandpiper (Actitis macularia), and southeastern shrew (Sorex longirostris) that might be more ecologically relevant, but for which no or only limited life history data are available. Organisms of this size also are representative of the young of larger birds and mammals that might regularly consume locally procured aquatic invertebrates. A scenario in which the receptor organism is a shrew-sized mammal or robin-sized bird consuming a diet composed entirely of the most contaminated organisms from the stretch or reach being considered typically yields a conservative wildlife risk estimate (that is, greatest indicated hazard) that is suitable for screening-level assessments. Such screening-level assessments based on conservative assumptions typically are conducted to determine whether or not more detailed investigations are warranted (USEPA, 1998).

Daily contaminant intake rates estimated as described can be compared to the TRVs either directly or as a ratio. The ratio, or hazard quotient (HQ), is obtained by dividing the daily contaminant intake rate by the TRV. HQ values that exceed 1.0 indicate risk. The no effect hazard concentration (NEHC) also can be computed. The NEHC is the dietary concentration at which the $\mathrm{HQ}=1.0$ in the species being evaluated; it is computed as the product of the weight-normalized food intake rate and the TRV (Hinck and others, 2006).

Food chain analysis has not yet been extended to coldblooded vertebrates (poikilotherms). Instead, measured concentrations in prey items often are compared to toxicity benchmarks as published in the scientific literature. The limited literature available (for example Woodward and others, 1994; Linder and others, 1998; Nagel and others, 2001; Hopkins and others, 2002) indicates that fish, reptiles, and amphibians generally are less sensitive to naturally incorporated dietary metals than small mammals and birds. Consequently, the NEHCs developed for robins and shrews (see SOP 5) are lower than published toxicity benchmarks for poikilotherms. Cadmium is an exception; James and others (2004) reported reduced survival of American toads (Bufo americanus) fed a diet of earthworms containing as little as $4.7 \mu \mathrm{g} / \mathrm{g}$ dry-weight. This value is virtually identical to the lowest NEHC computed for homeotherms $(4.8 \mu \mathrm{g} / \mathrm{g}$ dry-weight in crayfish, in the robin model), indicating that a lower NEHC ultimately may need to be developed for cadmium.

\section{Assumptions and Uncertainties}

Diet is the only exposure pathway considered in the screening-level assessments described here; however, the incidental ingestion of contaminated sediments by warm- and cold-blooded animals feeding on aquatic organisms from contaminated areas, along with the inhalation of contaminated dust and any water consumed by wildlife either through 
drinking or while feeding, may represent additional and important routes of exposure. For example, as much as 30 percent of the diet of sandpipers (Calidris spp.) may be composed of sediment (Beyer and others, 1994). When information on these other exposure pathways is available, daily contaminant intake rates computed from maximum measured concentrations typically are evaluated relative to LOAEL-based TRVs; daily intake rates based on mean concentrations are evaluated against NOAEL-based values (USEPA, 1993). However, the invertebrate metals data from ONSR represent composite samples of 10 animals of the same species, which are in effect means. Consequently, and lacking contemporaneous data describing the other exposure pathways, comparisons of daily contaminant intake rates computed from concentration maxima in composite samples to NOAEL-based TRVs represent conservative (that is, maximum) estimates of risk. Similarly, and as noted, exposure of fish and amphibians to waterborne metals also occurs; however, and with the possible exception of nickel and cobalt, significant waterborne exposure to metals would not be expected under the hard water conditions typical of ONSR.

There are numerous additional assumptions and sources of uncertainty inherent in wildlife food chain exposure analysis (Schmitt and others, 2006). First, it also is important to recognize that although there are consensus values for all five metals, alternative TRVs have been proposed and used elsewhere. Some TRVs are lower than the values used in this report; consequently, an evaluation that results in an HQ near or exceeding 1.0 (or a safety factor near or less than 1.0) based on these TRVs should be considered reason for further monitoring, investigation, or both. For example, and although the maximum 2005 ONSR concentrations in crayfish and Asian clams were low relative to mining areas in southern Missouri (Besser and others, 2007a; Schmitt and others, 2007b), some safety factors were small (see example in SOP 5). Further evaluation relative to other TRVs and exposure scenarios would, therefore, be warranted.

Crayfish were selected for monitoring because they represent a food source for many species. In contrast, Asian clams are not a significant component of the riparian wildlife food chain. The Asian clam was selected because this species accumulates most metals and because there are extant data for comparison. Nevertheless, the Asian clam is a filter-feeder, as are many other aquatic invertebrates. Metals concentrations in benthic insect larvae from streams draining the New Lead Belt of southeastern Missouri typically exceed those in crayfish; and concentrations of lead and cadmium, but not zinc, in small fish (largescale stoneroller, Campostoma oligolepis; and juvenile longear sunfish) typically exceed concentrations in invertebrates (Besser and others, 2007a). Consequently, metals concentrations in Asian clams may accurately represent dietary exposure concentrations for wildlife species that consume aquatic organisms containing greater concentrations than crayfish. Although the Asian clams are depurated prior to analysis, which can lower the concentration of lead relative to freshly collected clams, concentrations of other metals are not likely to be affected (Gunther and others, 1999; Angelo and others, 2007).

A wide range of body weights characterize the various life stages of birds and mammals. Moisture content of potential prey items also can vary. Values believed to be representative of southern Missouri were chosen from available data (see footnotes of table 6 in SOP 5). As noted, the exposure of and corresponding risk to smaller, younger animals would exceed that of adult animals, which could be especially problematic for nestling birds fed contaminated invertebrates.

As also noted, the assessment described here is based on one exposure pathway (diet). The incidental ingestion of contaminated sediments, inhalation of contaminated dust, and drinking water may represent additional and important routes of exposure that are not accounted for. Absent data for these pathways, the conservative alternative of comparing daily ingestion rates assuming a diet comprising 100 percent Asian clam or crayfish containing the maximum composite concentrations is employed. Although reasonable as a screening tool, this approach indicates only if harmful effects are possible, not if they are probable (Sample and Suter, 1999). Conversely, it is unlikely that the diet of adult animals of the receptor species modeled (or those they might represent as surrogates) would be entirely composed of invertebrates from one site, which is tacitly assumed in this approach. Nevertheless, the assumption may be more valid for nestling birds, which may be fed a large percentage of locally procured food items.

Much of the toxicological literature on metal toxicity to fish and amphibians is based on waterborne exposures. Collectively, these studies indicate that amphibians are at least as sensitive to dissolved metals as fish. The uptake of toxic, dissolved ionic metals by fish and amphibians across the gills or skin represents a significant route of exposure in situations where geochemical conditions favor these metal forms; however, the dissolved ionic forms of most metals associated with lead-zinc mining are generally not present in hard, carbonate-dominated, alkaline streams such as those in ONSR (Barks, 1978). Under these conditions, food chain transfer and dietary exposure are more important than waterborne exposure (Woodward and others, 1994; Farag and others, 1999; Besser and others, 2007a). Cobalt and nickel are exceptions; although present in relatively small amounts, these metals are more labile than lead, cadmium, and zinc, and can occur in dissolved form as free metal ions. Elevated concentrations of cobalt and nickel have been reported in sediment pore waters and biota in streams draining the Viburnum Trend (Brumbaugh and others, 2007; Schmitt and others, 2007a). In addition, much of what is known about dietary metals exposure in fish is based on studies conducted with Western salmonids (Woodward and others, 1994; Farag and others, 1999). More recent studies indicate that sculpins (Cottus spp.), which typically are abundant in Ozark streams, may be more sensitive to metals than salmonids (Woodling and others, 2002; Besser and others, 2007b). Sculpin density is low in streams draining the Viburnum Trend (Allert and others, 2005) and other mining areas (Woodling and others, 2002). 
As a final consideration, this assessment assumes that the five metals act independently. Lead, cadmium, zinc, and other metals co-occur throughout the mineralized areas of southern Missouri, and their effects are not necessarily independent or strictly additive either among themselves or together with other environmental factors such as temperature, nutrition, and disease (Joselow, 1980; Schmitt and others, 1984, 1993). Nevertheless, and in spite of the numerous assumptions and uncertainties noted, the values in table 6 represent conservative screening-level criteria for the assessment of potential adverse effects in wildlife from metals in aquatic invertebrates. As indicated by the example in SOP 5, application of the values to the 2005 ONSR pilot data (Schmitt and others, 2007b) indicates that the margin of safety for wildlife consumers of aquatic invertebrates is small for some metals associated with lead-zinc mining. Continued monitoring of metals in ONSR is, therefore, warranted. In addition, the field of ecological risk assessment is evolving rapidly, especially for reptiles and amphibians. Considering the apparent sensitivity of amphibians to cadmium (James and others, 2004), the present status of the Ozark hellbender in ONSR (MDC, 2007) and the fact that Ozark hellbenders feed predominantly on crayfish (Nickerson and Mays, 1973), pertinent sections of SOP 5 (including tables 5 and 6) should be reviewed and revised as necessary in association with each invertebrate collection cycle.

\section{Reporting}

Reports will summarize the most recent monitoring results and include a summary of data collected previously. The primary audience for these reports will be NPS resource managers and external scientists. An Executive Summary, highlighting key points for non-technical audiences, will be produced with each report. The primary audience for the Executive Summary will be Park Superintendents, interpreters, and the general public. Peer review for both will be conducted internally by HTLN staff. Reports will be produced each time monitoring is conducted (every 5 years). To disseminate findings in a timely manner, reports will be completed by September 1 of the year following data collection. Report distribution is described in SOP 6.

\section{Personnel Requirements and Training}

\section{Roles and Responsibilities}

The aquatic program leader serves as the project manager for implementing this monitoring protocol, and is supervised by the HTLN network coordinator. Because of the need for consistency in implementing the protocol, the project manager usually will oversee sample collection. The data management aspects of the monitoring effort is the shared responsibility of the project manager and the data manager. Typically, the project manager is responsible for data collection, entry, verification, validation, summarization, analysis, and reporting.
The data manager is responsible for data archiving, security, dissemination, and database design. The data manager, in collaboration with the project manager, also develops data entry forms and other database features as part of quality assurance and automates report generation. The data manager is ultimately responsible for ensuring that QA and QC procedures are built into the database management system and that appropriate data handling procedures are followed.

\section{Qualifications and Training}

The collection of credible, high-quality trace-metal data requires attention to detail with respect to where and when samples are collected, protection of the samples from external contamination, and data recording and transcription. Therefore, it is essential that the samples be collected from the assigned sites at the designated time of year, that the collection locations are well documented, and that personnel follow the clean procedures identified in this protocol and its associated SOPs to prevent external contamination. Information with which to determine whether or not trace metal concentrations vary among the crayfish and freshwater bivalve species of ONSR is limited; consequently, it may or may not be important to be able to correctly identify crayfish and Asian clams in the field. It is nevertheless best to err conservatively by assuming that species-level differences exist; specimens should be correctly identified in the field, and samples should not comprise mixed species. Differences in trace metal concentrations between genders of crayfish or Asian clams have not been reported; however, differences between genders have been reported in fish (Schmitt, 2004), so it would not be unreasonable to expect similar differences in freshwater invertebrates. Regardless, differentiating between invertebrate genders is often not possible, especially during the recommended late summer-early fall collection period. Also important is attention to detail with respect to recording and data entry. Time will be budgeted for field personnel to learn to identify crayfish and mollusks, and to verify data entry.

\section{Operational Requirements}

\section{Annual Workload and Field Schedule}

Crayfish and Asian clam collection should begin no sooner than the last full week of August and be completed by the end of the first full week of October to minimize exposure variation among sites and to ensure that crayfish of the correct size are obtained. Inclement weather, high water levels, and personnel workloads will preclude the scheduling of sampling to specific dates. Sampling dates should be scheduled and logistics organized before the start of each field season (SOP 1). 


\section{Facility, Equipment, and Personnel Needs}

Invertebrate collections do not require special facilities beyond normal office space and equipment storage needs. A chest-type freezer with enough capacity to store samples before shipment to the analytical laboratory is required. SOP 1 contains a list of field equipment and supplies needed for one crew. If two or more crews work simultaneously, equipment requirements will increase accordingly.

Personnel estimates for field work are based on a crew of two people: an aquatic ecologist to collect and identify the organisms, and a bio-technician to record data and process samples (table 2).

Time and budget are contingent upon the amount of time required to travel to the sites and to locate and collect the animals. Sample processing requires about 1 hour per site in the field. Another hour (for each person) is required at the end of each trip to log in the samples; verify, copy, and file data sheets; enter data; and clean and store equipment. Startup costs include the purchase of the equipment and supplies listed in SOP 1, as well as maintenance and replacement of equipment shared among multiple projects (such as GPS units, cameras, waders, and raingear). As noted, equipment should be labeled for use only at ONSR to minimize the potential spread of invasive species.

\section{Procedure for Revising the Protocol and Archiving Previous Versions of the Protocol}

Revisions to the Protocol Narrative and specific SOPs are to be expected. Careful documentation of changes, and a library of previous protocol versions are essential for maintaining consistency in data collection, and for appropriate treatment of the data during data summary and analysis. The Microsoft (MS) Access database for each monitoring component contains a field that identifies which version of the protocol was being used when the data were collected.

The rationale for dividing a sampling protocol into a Protocol Narrative with supporting SOPs is based on the following:

1. The Protocol Narrative is a general overview of the protocol that gives the history and justification for doing the work and an overview of the sampling methods, but that does not provide all of the methodological details. The Protocol Narrative will be revised only if substantial changes to the protocol are required.

2. The SOPs, in contrast, are specific step-by-step instructions for performing a given task. They are expected to be revised more frequently than the protocol narrative.

3. When a SOP is revised, in most instances it is not necessary to revise the Protocol Narrative to reflect the specific changes made to the SOP.

Table 2. Estimated personnel, travel, and analytical resources, per collection.

[Collection period varies; based on 30 composite samples from five locations with three samples of each taxon from each location]

\begin{tabular}{|c|c|c|}
\hline Budget item & Quantity & Estimated cost (2008) \\
\hline \multicolumn{3}{|c|}{ Personnel } \\
\hline \multicolumn{3}{|l|}{ Field crew } \\
\hline Aquatic ecologist, STF & 72 hours & 1,270 \\
\hline Seasonal biological technician & 72 hours & 1,075 \\
\hline \multicolumn{3}{|l|}{ Administrative support } \\
\hline Quantitative ecologist & 8 hours & 250 \\
\hline GIS specialist & 8 hours & 173 \\
\hline Data manager & 8 hours & 250 \\
\hline Administrative assistant & 16 hours & 262 \\
\hline \multicolumn{3}{|c|}{ Travel and miscellaneous } \\
\hline Chemical analysis (includes quality assurance and sample containers) & 30 samples & $\$ 16,000$ \\
\hline Total & & $\$ 23,227$ \\
\hline
\end{tabular}


4. All versions of the Protocol Narrative and SOPs will be archived by the HTLN.

The steps for changing the protocol (either the Protocol Narrative or the SOPs) are outlined in SOP 8. Each SOP contains a Revision History Log that should be filled out each time a SOP is revised to explain why the change was made, and to assign a new version number to the revised
SOP. The new version of the SOP or Protocol Narrative will then be placed on the NPS Inventory \& Monitoring website (http://science.nature.nps.gov/im/monitor/protocoldb.cfm). Revised versions of the protocol and SOPs will not be subjected to USGS peer review and, therefore, will not constitute USGS publications. 


\section{Standard Operating Procedure 1: Preparation for Sampling, Version 1.0 (July 28, 2008)}

\section{Revision History Log}

\begin{tabular}{|l|l|l|l|l|l|}
\hline $\begin{array}{c}\text { Previous version } \\
\text { number }\end{array}$ & Revision date & Author & Changes made & Reason for change & New version number \\
\hline & & & & & \\
\hline & & & & & \\
\hline & & & & & \\
\hline & & & & & \\
\hline
\end{tabular}

\section{General Preparation and Review}

1. Before the field season each year, all study participants should review the current version of the entire protocol, including the SOPs.

2. Review of crayfish and mussel identification is important; misidentification of a species may affect trace metal concentrations. In addition, a rare animal may inadvertently be killed. Misidentification is more serious than slight deviations from specified organism size or failing to collect the 30 specimens of each type. Be sure to make a positive identification, and do not combine different species within a composite sample. Fourteen species of crayfish are known to inhabit the Current River/Jacks Fork system, including several rare species (see Pflieger, 1996, or http://mdc.mo.gov/nathis/arthopo/crayfish/varcraw.htm). Many are similar in appearance. In contrast, Asian clams are readily distinguished from the other 13 (indigenous) mussel species present in the Current River/Jacks Fork system by their thick shells of rounded triangular shape and the series of heavy concentric ridges originating at the hinge area (Oesch, 1995; see photo at http://www.mdc. mo.gov/fish/watershed/current/biotic/). These sources should be consulted before starting each collection.

3. Review the instructions for using the GPS units, located online at:

http://science.nature.nps.gov/im/units/htln datamanagement.cfm

4. Obtain the necessary scientific collection permits. Permit requirements vary depending on the organization or agency doing the collection. Applications for these permits must be submitted early in the sampling year to ensure approval. Missouri Department of Conservation (MDC) permit requests should be submitted to:

Missouri Department of Conservation

P.O. Box 180

Jefferson City, MO 65102-0180

(573) 751-4115

Permit applications can also be obtained online at:

http://mdc4.mdc.mo.gov/Documents/8908.doc

5. Preseason planning facilitates the successful and timely completion of collections; scouting sites in advance to locate crayfish and Asian clams usually is advantageous.

6. Notebooks from previous collections should be reviewed if available to identify any unique events that may be encountered. A field notebook for the survey year should be prepared with pages for entry of sampling schedules, observer names, field hours, and unique happenings that may have affected how the data are reported. Trip reports are based on information recorded in field notebooks so it is imperative that they are clearly organized for ease of field note entry.

7. Prior knowledge of species most likely to be encountered will aid collectors in preparing for the field season; therefore, species lists from previous collection efforts in the park or local area should be compiled and compared to reference manuals to identify species not recorded that have a probability of being recorded. Copies of these combined species lists should be carried into the field as quick references in helping to identify unknown species.

8. A list of waypoints representing the downstream-most boundaries of stretches to be sampled should be carried into the field to ensure sampling begins at the appropriate locations. A list of waypoints representing crayfish or Asian clam concentration areas within each stretch also may be helpful for locating target organisms in subsequent years. 


\section{Scheduling Field Work}

1. Crayfish and Asian clam collections should begin no sooner than the last full week of August and be completed by the end of the first full week of October. Inclement weather, high water levels, and personnel workloads will preclude the scheduling of sampling events to specific annual dates. Sampling dates should be scheduled and logistics organized before the start of each field season.

2. Sample collection requires a two person crew (both members to sample; then one to identify and measure organisms, the other to record data). Time per site depends on availability of crayfish and Asian clams; processing time is 1 hour or less.

3. If access across private lands is necessary to reach sites, the prior consent of landowners should be obtained before entry; record the time and place of such entries along with the name, address, and telephone number of the person providing the consent on the data sheet.

\section{Organizing Supplies and Equipment}

1. All of the equipment and supplies listed in this SOP should be organized and made ready for the field season several weeks in advance. This allows time to make needed repairs and order equipment and supplies. A list of field equipment and supplies needed for one crew (two people) to collect crayfish and Asian clams at one site is given in table 3 . If two or more crews work simultaneously, the equipment needs will change accordingly.

2. Copies of the field data forms and sample labels (appendixes 1 and 2) should be made on Rite-in-the-Rain ${ }^{\circledR}$ paper in advance of need. A supply of invertebrate sampling data forms (appendix 1) and sample labels (appendix 2), the protocol narrative, and the SOPs copied to or printed on Rite-in-the-Rain paper also should be available for field use.

\section{Pre-Sampling Procedures}

1. Review the list of equipment and supplies (table 3 ) to be certain that everything on the list is available. Note that numbers in the tables are minima; spares of important items (such as calipers) are advisable. Check the status and condition of the oxygen bottle and regulator; if in doubt, get the bottle refilled. Safety note: Secure the oxygen bottle in the vehicle during transport.

2. Prior to the day of sampling, determine which sites will be sampled, and make a list of the easting and northing (UTMX and UTMY) coordinates for those sites; bring the list into the field. Reminder: The Asian clams need to be allowed to depurate (purge particulate material) for 24 hours following collection; plan accordingly (that is, it is best to sample not later in the week than Thursday).

3. If sampling is to be conducted under an MDC Wildlife Collectors Permit, notify the Conservation Agent in the county where sampling will occur in advance of sampling. Reminder: The permittee must be present during the collections.

4. Crayfish samples need to be either stored on ice or frozen in dry ice while in the field. Ascertain that you have sufficient ice or dry ice for the number of sites to be visited. Check the ice or dry ice regularly, and know where to get more should the need arise. Safety note: Dry ice is dangerously cold; avoid skin and eye contact. Personnel handling samples and containers in dry ice should wear insulated gloves. Dry ice also needs to vent $\mathrm{CO}_{2}$ to the atmosphere; do not store it in tightly sealed containers or in confined spaces.

5. It generally is advantageous to prepare labels on Rite-inthe-Rain paper (appended to the protocol) in advance for each site. Each label should bear the site number, taxon (crayfish or Asian clam), date, and the composite sample identification (letter A, B, or C). Write with a ball-point pen or permanent felt-tipped marking pen (Sharpie ${ }^{\circledR}$ or equivalent). Labels should be attached to jars using 2-inch clear plastic tape; wrap completely around the jar to protect the label from moisture and abrasion. If such tape is unavailable, write on both the jar and lid with a felt-tipped pen. To prevent contamination, labels must never be placed inside of bags or jars containing samples. 
Table 3. Field equipment and supplies for collecting crayfish and Asian clams.

[Minimum quantities; *, items for which spares or extra are advised]

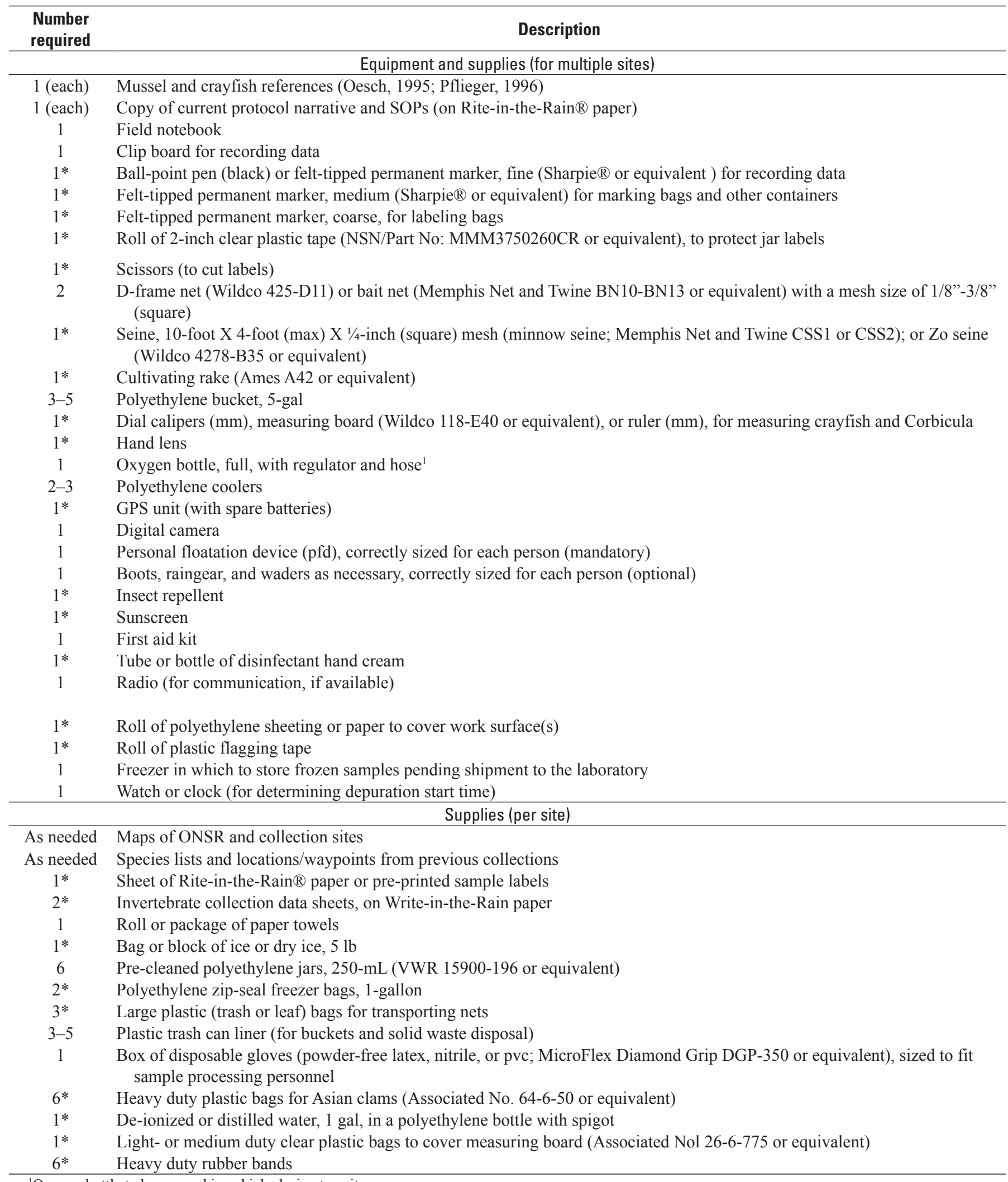

${ }^{1}$ Oxygen bottle to be secured in vehicle during transit. 


\section{Standard Operating Procedure 2: Collecting, Processing, and Preparing Samples of Crayfish and Asian Clams, Version 1.0 (July 28, 2008)}

\section{Revision History Log}

\begin{tabular}{|l|l|l|l|l|l|}
\hline $\begin{array}{c}\text { Previous version } \\
\text { number }\end{array}$ & Revision date & Author & Changes made & Reason for change & New version number \\
\hline & & & & & \\
\hline & & & & & \\
\hline & & & & & \\
\hline & & & & & \\
\hline & & & & & \\
\hline
\end{tabular}

\section{Safety Note}

Because working in or near water is potentially hazardous, a minimum of two people is required to conduct these procedures. Personal flotation devices (PFDs) are required for all personnel regardless of season. Note also that kicknetting or seining may require the manipulation of rocks and other debris with the feet; boots or waders are, therefore, also strongly recommended regardless of season.

\section{Additional Notes}

The following should be kept in mind while collecting and processing specimens:

1. Transport the collection equipment (nets) in plastic trash bags between sites to keep them clean (and other items dry).

2. Cover your work surface (table, cooler top, vehicle tailgate) with a clean piece of plastic sheeting or paper. Wear disposable gloves when processing samples, and replace them between sites or when they become torn.

3. Place the measuring board inside a clear plastic bag. To prevent contamination, perform all measurements on the bag-covered board on the covered work surface.

4. Line buckets to be used for transporting organisms with a plastic bag (polyethylene tall-kitchen trash bag or equivalent).

\section{Procedures}

5. Find the stretch of river to be sampled. Use GPS to locate the lower geographic boundary of the stretch, which is given in table 1 of the protocol narrative. (Note: beginning and ending points of stretches often correspond to tributary confluences, which may help to locate the lower boundary in the field). For instructions on using the GPS, refer to the GPS SOP available online at $h t t p: / /$ science. nature.nps.gov/im/units/htln/datamanagement.cfm

6. Locate the first riffle above the lower geographic boundary. The area that will be sampled includes the next three riffles located in consecutive order upstream from the first riffle above the lower boundary of the stretch.

7. Site names are designated by the first four characters of the river name (CURR, JACK), Mainstem (M) or Tributary (T), and the site number. Mainstem sites will be labeled in successive order from upstream to downstream. Example: JACKM03 is the 3rd mainstem site on the Jacks Fork. The locations of sampling sites, sample site codes, and GPS coordinates can be found in fig. 1 and table 1 of the protocol narrative.

\section{Crayfish}

1. Crayfish are obtained by kick-netting or kick-seining in coarse-substrate riffles or along the edges of emergent vegetation beds. Note: avoid walking through areas to be sampled. To kick-seine, unwind the net to a manageable length (usually 1 to $2 \mathrm{~m}$ ). Orient the net vertically (weighted line down) and perpendicular to the current; stretch it as wide as one person can manage, and leave the excess net wrapped around the poles. Ensure that the weighted line remains on the bottom by placing rocks along the inside of the net. While the net is held open, the other team member walks downstream toward the net, overturning rocks or disturbing vegetation with his or her feet along the way to dislodge the crayfish and allow them to be swept into the net by the current. If more personnel are available, the net can be expanded to sample a larger area. A cultivating rake also can be used in lieu of the feet to manipulate the rocks. When the kicker(s) reach(es) the net, all team members lift the net in unison from the water 
horizontally and take it to shore, where the crayfish are removed by gloved hand, rinsed, and placed into a plasticlined bucket containing stream water. Fish and other organisms are immediately released back into the stream. The kick-netting process is similar, but the $\mathrm{D}$-frame net can be operated by one person. The lower edge of the net is placed on the stream bottom, downstream from rocks or vegetation, which are then dislodged with the foot. When at least 10 specimens of suitable size (18 to $25 \mathrm{~mm}$ carapace length) have been obtained, return to shore with the bucket to begin processing the crayfish.

2. Remove crayfish from the bucket one at a time with a gloved hand and examine each specimen (with a hand lens if necessary) to confirm species identities according to the characteristics presented by Pflieger (1996). This reference also contains color photographs and range maps of Missouri crayfish species. The photographs and range maps can also be viewed online at http://www.mdc.mo.gov/nathis/arthopo/crayfisht varcraw.htm It is important to note that many of the structural features that definitively distinguish crayfish species are not evident during late summer and early fall. Nevertheless, and as noted by Pflieger (1996), knowledge of the collection location (that is, river basin) and information on coloration can distinguish between most species at a given site. Fourteen species of crayfish are known to inhabit the Current River and Jacks Fork. Crayfish of the recommended size obtained from riffles within ONSR will most likely be golden crayfish. This species is similar in size and general appearance to the Ozark crayfish (O. ozarkae), which is usually less abundant. Both species bear two dark, saddle-like marks that differentiate them from other species likely to be encountered within ONSR. However, the claws (chelae) of the golden crayfish lack spots or blotches; those of Ozark crayfish are usually speckled (covered with black spots), which may also be present on the abdomen. Spothanded crayfish (O. punctimanus), which also are common, is readily distinguished from golden and Ozark crayfish by the presence of a single dark spot at the joint of the claws. The only other species likely to be encountered is Hubbs' crayfish (Cambarus hubbsi), which can be distinguished by its stout body form and claws relative to the Orconectes spp. In the event that golden crayfish (the preferred species) are not available, the order of preference for alternated species is spothanded, crayfish, Ozark crayfish, and Hubbs' crayfish. Note: if a specimen cannot be identified in the field, release it and collect more if necessary to fill out the sample. However, do not mix species within a sample.

3. After confirming the identity of the specimen, rinse it carefully in stream water, measure its carapace length $(\mathrm{mm})$ with the calipers (on the bag-covered measuring board) and record the species and carapace length on the data sheet. Carapace length is the distance from the tip of the rostrum to the posterior edge of the carapace; a diagram illustrating how it is measured appears on p. 34 of Pflieger (1996). Use the following codes, which correspond to the genus and species names (table 4), to identify the species: golden crayfish, OL; spothanded crayfish, OP; Ozark crayfish, OO; Hubbs' crayfish, $\mathrm{CH}$.

4. Place the 10 crayfish collected per riffle into a precleaned, pre-labeled jar. Repeat this procedure until all three samples (one per riffle) of 10 specimens of the appropriate size (18 to $25 \mathrm{~mm}$ ) have been obtained.

5. Crayfish are separated into lots of 10 specimens per each of three riffles sampled. Again, do not mix species within a sample; if 10 specimens of golden crayfish cannot be obtained in a given riffle, retain all that are collected. The alternate species may be substituted in the order of preference identified previously, but different species should be placed in separate containers (that is, they are separate samples).

6. Thoroughly clean the net(s) and bucket(s) in stream water to remove all vegetation and sediment. Rinse the bag-covered measuring board in stream water, then with de-ionized or distilled water; replace the bag if it is damaged or dirty.

7. Rinse your gloved hands in stream water, then with deionized or distilled water. Inspect and replace the gloves if they are torn or damaged.

8. If the samples will be frozen in dry ice, place them directly in the cooler. If wet ice is used, put the three jars in a plastic bag to protect them from water, then place them in the cooler.

\section{Asian Clams}

1. Asian clams (Corbicula fluminea) are located visually, then collected from riffles, their associated backwaters, or vegetation beds by hand and held in lined buckets of ambient water for processing. Asian clams are readily distinguished from the indigenous mussel species present in the Current River Basin by their thick shells of rounded triangular shape and the series of heavy concentric ridges originating at the hinge area. Photographs are available in Oesch (1995) and at http://cars.er.usgs.gov/corbicula4. bd] Asian clams often occur in dense colonies. The clams attain a maximum size of about $38 \mathrm{~mm}$ in diameter. Specimens of 15 to $25 \mathrm{~mm}$ (greatest diameter) are suitable for monitoring. If Asian clams cannot be obtained, there will be no sample; there is no alternate species, but Asian clams outside the preferred size range are preferable to no sample.

2. Asian clams are processed in a manner similar to that described for crayfish, except that they must be depurated (allowed to purge themselves of particulate material) 
for 24 hours before processing. Each Asian clam sample comprises 10 specimens from a riffle (one sample from each of the three riffles sampled). After 10 clams have been collected from a riffle, they should be transferred to shore in the plastic-lined bucket. While wearing gloves, begin processing the specimens by manually removing as much debris from the shells as possible. Rinse them in stream water, then confirm the identity of each specimen. Measure its greatest shell diameter (width, in $\mathrm{mm}$ ) either with the calipers or with the bag-covered measuring board. Record the species (use CF as the code for Asian clam; table 4) and diameter on the data sheet. Place the specimens in an $8 \times 6 \times 18$ inch, 4-mil gusseted polyethylene bag (Associated Bag Co., Milwaukee, Wisconsin no. 64-6-50, or equivalent) about one-third full of ambient water (one for each composite sample). When 10 specimens have been placed in the bag, fill the bag with oxygen from the bottle, double-twist the end, and seal the bag tightly with a heavy-duty rubber band. Place this bag in another bag, add the sample label, and seal the outer bag with another rubber band. Place the labeled, doublebagged samples in a cooler containing ambient water. Keep the cooler in a shaded location.

3. Rinse the bucket in stream water. Rinse the bag-covered measuring board in stream water, then with de-ionized or distilled water; replace the bag(s) if damaged or dirty.

4. Rinse your gloved hands in stream water, then with deionized or distilled water. Inspect and replace the gloves if they are torn or damaged. Repeat steps 1-4 until all three samples have been obtained.

5. When sampling has been completed, the team leader should review and sign the data sheet after ascertaining that all required information has been recorded; be certain that the collection times have been recorded, especially for the Asian clam samples. Remove the cover from the work surface and place it and all other disposable items (gloves, paper towels, etc.) in one of the bucket liners and retain all for later disposal. If time permits, prepare a sketch of the site in the notebook or on the back of one of the data sheets; indicate in the sketch the general locations from which the samples were obtained.

6. Thoroughly clean and inspect all sampling equipment to ensure that no organisms remain attached.

Table 4. Species codes for invertebrate samples.

\begin{tabular}{cll}
\hline Species code & \multicolumn{1}{c}{ Common name } & \multicolumn{1}{c}{ Scientific name } \\
\hline OL & Golden crayfish & Orconectes luteus \\
OP & Spothanded crayfish & O. punctimanus \\
OO & Ozark crayfish & O. ozarkae \\
CH & Hubbs' crayfish & Cambarus hubbsi \\
CF & Asian clam & Corbicula fluminea \\
\hline
\end{tabular}




\section{Standard Operating Procedure 3: After the Field Collections, Version 1.0 (July 28, 2008)}

\section{Revision History Log}

\begin{tabular}{|l|l|l|l|l|l|}
\hline $\begin{array}{c}\text { Previous version } \\
\text { number }\end{array}$ & Revision date & Author & Changes made & Reason for change & New version number \\
\hline & & & & & \\
\hline & & & & & \\
\hline & & & & & \\
\hline & & & & & \\
\hline
\end{tabular}

\section{Procedures}

1. Upon return to the duty station, all crayfish samples and the Asian clams that have completed depuration (see item 2, following) should immediately be transferred to a freezer $\left(-20^{\circ} \mathrm{C}\right)$. If a freezer is not immediately available, the samples should be frozen in dry ice until one is available. Samples should be inventoried by checking the appropriate box on the data sheet as each is transferred from the cooler(s) to the freezer. Samples should be maintained frozen $\left(-20^{\circ} \mathrm{C}\right)$ until they are shipped to the analytical laboratory. Review and sign the field data sheet again, verifying that the samples have been logged in and frozen. Photocopy the data sheets and store them in properly designated areas, preferably in different buildings to protect against loss, fire, flood, theft, or other unforeseen events. Dispose of all used expendables as trash.

2. After 24 hours of depuration, transfer the Asian clams to jars. Transfer each sample label from the outer holding bag to a jar and fasten the label to the jar with clear polyethylene tape. While wearing disposable gloves, transfer the Asian clams from the bag to the labeled jar. Repeat for all samples. If the samples will be stored on wet ice, place the three jars from the site in a plastic bag to protect them from water; otherwise, freeze them immediately. Record the time of the transfer on the data sheet.

3. Complete any logbook or notebook entries. Photocopy appropriate logbook pages and file the copies with the duplicate data sheets. At the end of each field trip, file a trip report with the data manager outlining hours worked, field-crew members and their responsibilities on the project, and any unique situations encountered. File a copy of the report with the copies of the data sheets. This information is incorporated in the database and used during data analysis; it is critical for identifying discrepancies and inconsistencies in the data. The project manager is responsible for filing all field reports.

4. Samples are shipped to the analytical laboratory only upon receipt of instructions. (Note: the analytical laboratory may not be the same for all collections.) Ship samples frozen, in properly labeled coolers containing enough dry ice to maintain them frozen in transit (generally a quantity equal to the weight of the samples) to the analytical laboratory via Federal Express (FEDEX). Initiate a chain-of-custody form (appendix 3) and ship it with the sample. Request that it be signed and returned upon receipt by the laboratory, then copy and file it with the data sheets. Note: Dry ice is considered a hazardous material for which special shipment restrictions and regulations apply. The regulations are subject to change; consult FEDEX (http://www.fedex.com) for current instructions before shipment.

5. Thoroughly rinse (in tap water) and re-inspect all watercontact equipment (including boots, nets, buckets, coolers, and PFDs) for the presence of attached organisms. Spread the equipment and allow it to air-dry completely. 


\section{Standard Operating Procedure 4: Data Management, Version 1.0 (July 28, 2008)}

\section{Revision History Log}

\begin{tabular}{|l|l|l|l|l|l|}
\hline $\begin{array}{c}\text { Previous version } \\
\text { number }\end{array}$ & Revision date & Author & Changes made & Reason for change & New version number \\
\hline & & & & & \\
\hline & & & & & \\
\hline & & & & & \\
\hline & & & & & \\
\hline & & & & & \\
\hline
\end{tabular}

This SOP explains procedures for the management of ONSR metals data. It includes a general description of the data model and procedures for data entry, data verification and validation, and data integrity for the primary metals data.

Data management can be divided into the initial design phase that involves defining the data model, its entities and their relations; and the procedures necessary to implement the database. Microsoft (MS) Access 2003 is the primary software used for maintaining metals data. The metals data will be stored in the National Park Service's NPStoret database. Spatial data associated with field sampling locations are managed with ESRI ArcInfo 9.x. Data products derived from this project will be available at the NPS I\&M Data Store and the USEPA STORET National Data Warehouse (http://www.epa. gov/storet/dw home.htm ). Quality-assurance (QA) and quality-control (QC) guidelines for data management described in this document are based on recommendations of Rowell and others (2005) and references cited therein.

\section{Data Model}

The NPS I\&M program has designed the Natural Resource Database Template (NRDT) to be used as a database model for storing vital signs monitoring data in MS Access (NPS, 2006). The template has a core database structure that standardizes location and observation data to facilitate the integration of datasets. Developed in MS Access, the database allows users to enter, edit, display, summarize, and generate reports, as well as integrate with other Natural Resource data systems such as NPStoret. The NRDT data dictionary follows standards identified in the NRDT phase 2 and is modified where required. Naming conventions follow I\&M recommendations.

The aquatics program relies on distributed databases to allow remote users to enter data and is accomplished via database replication consisting of a design master and replicas. The design master is stored on the server at Missouri State University in Springfield, Missouri, and is used for local data entry, revisions, and design changes. A replica is created for users without access to the server and is distributed for data entry activities. When a user has finished data activities with the replica, it is returned and synchronized with the design master. The NPS Water Resource Division (WRD) also has designed the NPStoret database to facilitate archiving NPS data in the EPA Storet database. NPStoret is a series of Accessbased templates patterned after the NRDT that includes data entry templates and an import module. It supports the core data management objectives of data entry and verification/ validation in a referentially constrained environment (that is, related locations, events, and primary data elements) (NPS, 2007). The sampling events (tbl_SamplingEvents) and locations (tbl_Locations) tables are the two core tables and contain general information pertaining to the field sample occasion; they include information such as date and time, river stretch ID and UTM coordinates, and park/project codes. Detailed information pertaining to the Asian clam (Corbicula fluminea) or crayfish sample is maintained in tbl_CorbiculaData, tbl CorbiculaMetals, tbl_CrayfishData, and tbl_CrayfishMetals. Other tables include administrative and personnel data and a species lookup table.

\section{Data Preparation}

Procedures for QA and QC related to data recording are important components of any project. Sampling data (such as sample methods, water-quality conditions, and speciesmeasurement data) are recorded and checked for completeness either before leaving a site or within 24 hours of data recording. This will aid in verification and validation of the data after entry into the database. To prevent the complete loss of field form data because of unforeseen circumstances such as fire or flood in the workplace, all field sheets are photocopied, and a hard copy located in a location separate from the originals. Field sheets are scanned, and electronic copies of the data sheets are stored on the HTLN server located at Missouri State University. This will ensure that at least one copy is available for data entry and verification. 


\section{Data Entry}

Data entry is accomplished in either the design master or replica databases using a tiered set of forms. Upon opening the replica, a "switchboard" directs the user to a preliminary set of forms that define the sampling occasion and requires the input of sampling periods and events before entry of additional data. The other forms address the details of elemental contaminant occurrence, organism measurements, observers, and so forth, and have data entry instructions. Once all fields for the preliminary set of forms have been completed, data can be entered for the remaining forms. When using replicas for data entry, the replica is synchronized with the master database so that new data are added. Note: The "Prevent Deletes" option is enforced in replica databases to ensure that data are not inadvertently lost.
Several features are built-in to form properties that enable the user to maximize data entry efforts while minimizing error. Data input masks for ease of viewing multi-part data (park/project codes and date in PeriodID or EventID), "fillin-as-you-type" to automatically complete a field, limiting input values to known ranges (or restricting null values) or providing "drop-down boxes," highlighting data entry boxes being edited, and tab indexes to control the order of data entry. Forms also contain fields that require data input and/or are constrained to properties and integrity of related tables. 


\section{Standard Operating Procedure 5: Data Analysis, Version 1.0 (July 28, 2008)}

\section{Revision History Log}

\begin{tabular}{|l|l|l|l|l|l|}
\hline $\begin{array}{c}\text { Previous version } \\
\text { number }\end{array}$ & Revision date & Author & Changes made & Reason for change & New version number \\
\hline & & & & & \\
\hline & & & & & \\
\hline & & & & & \\
\hline & & & & & \\
\hline & & & & & \\
\hline
\end{tabular}

\section{Parameter Estimation}

The most basic data analyses will consist of plotting means and ranges of metal concentrations in Asian clams and crayfish from each stretch with time. If desired, standard errors and confidence intervals also can be computed around the means; however, and as noted in the narrative, an overall mean for ONSR will not be computed.

\section{Control Charts}

The construction and interpretation of control charts is described in many texts focusing on industrial quality control (Beauregard and others, 1992; Gyrna, 2001; Montgomery, 2001). The application of control charts for environmental monitoring is discussed in texts by McBean and Rovers (1998) and Manly (2001), and in a review by Morrison (2008). These sources, or an analyst familiar with control charts, should be consulted before actual control chart construction.

Although control limits often are based on values from a statistical sampling process, the control limits will be set based on toxicity thresholds developed as described in the protocol narrative. It is important to recognize that this approach is not based on a statistical distribution, and therefore probabilities cannot readily be associated with the observations. A generic control chart is illustrated in figure 2 . If variations are desirable or necessary, a statistical analyst familiar with control charts should be consulted.

The control chart represents a basic data set summary indicating which variables are in the greatest need of more indepth analyses or management action. Control charts contain only upper control limits representing toxicity thresholds for invertebrate metals concentrations associated with dietary risk to riparian wildlife. The toxicity thresholds have been determined through food chain analysis using procedures developed for conducting ecological risk assessments (USEPA, 1992, 1997, 1999, 2007b).

The rationale and assumptions associated with food chain analysis for warm-blooded vertebrates are described in the "Toxicity Threshold Development" section of the protocol narrative. Food chain analysis is based on TRVs for the met- als of interest. These represent daily contaminant intake rates associated with toxicity in representative wildlife species. The TRVs used here are consensus NOAEL values developed by the USEPA in support of Ecological Soil Screening Levels (Eco-SSLs) for metals. Current (May 2008) values are listed in table 5 .

The other component(s) of food chain analysis are the daily food intake (DI) rates of the wildlife species being modeled. Values for the receptor species used here (American robin, Turdus migratorius; great blue heron, Ardea herodias; short-tailed shrew, Blarina brevicauda; and American mink, Mustela vison) were obtained from the "Wildlife Exposure Factors Handbook" (USEPA, 1993) and are identified in the footnotes of table 6 .

The measured concentrations in Asian clams and crayfish are compared to the toxicity thresholds, which represent NEHCs. The NEHCs in table 6 have been computed from

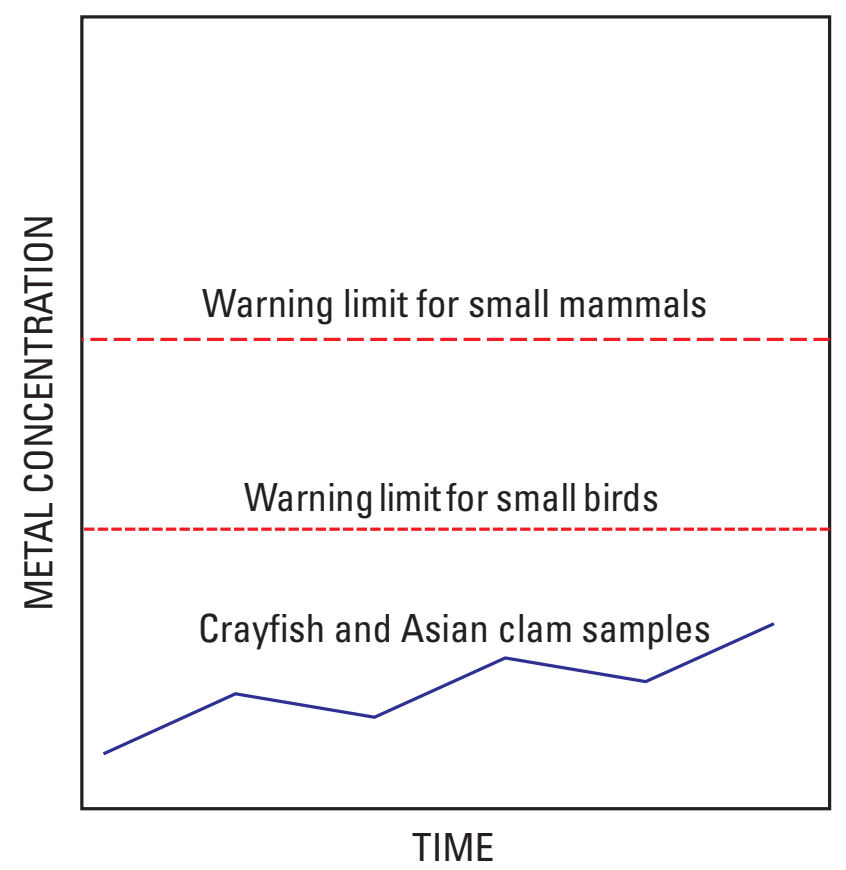

Figure 2. Example control chart for tracking concentrations of metals in crayfish and Asian clam. 
the TRVs and DIs as wet-weight and dry-weight values as described in the "Toxicity Threshold Development" section of the protocol narrative. The comparisons can be made either directly (between measured concentrations and NEHCs) or by computing "safety factors" (maximum measured concentration $\div \mathrm{NEHC}$ ).

\section{Example Based on 2005 Data}

Maximum 2005 concentrations of cadmium, cobalt, lead, nickel, and zinc in crayfish and Asian clams from ONSR (Schmitt and others, 2007b) are presented in table 5. The NEHCs computed for the four receptor species are presented in table 6. The NEHCs are presented in wet weight and dryweight units to facilitate comparisons with invertebrate metals data from ONSR, which are measured in dried samples and reported in dry-weight units; for budgetary reasons, moisture (water) content is not determined. Dry-weight NEHCs for Asian clams and crayfish were computed using approximate moisture values obtained from the scientific literature (Belanger and others, 1986; Graney and Giesy, 1988; Schmitt and others, 2006; table 6). The generally large safety factors $(>10)$ indicate a relatively low risk level for most metals in both taxa (table 6). The exceptions are for cadmium and zinc risk to small mammals and birds and nickel risk to small mammals (table 6). These comparatively small safety factors $(<10)$ reflect both the large uncertainty in the process, but also that further monitoring of cadmium and zinc is warranted.

As noted previously, the NEHCs for the metals and wildlife species identified in table 6 were based on TRVs and exposure factors that were current at the time this document was prepared (May, 2008); however, the Eco-SSLs and the TRVs upon which they are based, along with other data used in the analysis, are subject to revision. In addition, the process of risk assessment as it applies to cold-blooded vertebrates (fishes, amphibians, and reptiles) is evolving rapidly. Conse-

Table 5. No observed adverse effect level toxicity reference values for metals in mammals and birds, and maximum 2005 concentrations in crayfish (Orconectes luteus) and Asian clam (Corbicula fluminea) from Ozark National Scenic Riverways.

[TRV, toxicity reference value; from the U.S. Environmental Protection Agency (USEPA, 2005a, 2005b, 2005c, 2007a, 2007c). Concentrations in crayfish and Asian clam from Schmitt and others (2007c)]

\begin{tabular}{lccccc}
\hline \multirow{2}{*}{ Metal } & \multicolumn{2}{c}{ TRV $(\mathbf{m g} / \mathbf{k g} / \mathbf{d})$} & & & \multicolumn{2}{c}{$\begin{array}{c}\text { Maximum concentration } \\
\text { (mg/kg dry weight) }\end{array}$} \\
\cline { 2 - 3 } \cline { 6 - 6 } & Mammals & Birds & & Crayfish & Asian clam \\
\hline Cadmium & 0.77 & 1.47 & & 0.77 & 3.34 \\
Cobalt & 7.33 & 7.61 & & 1.27 & 2.00 \\
Lead & 4.70 & 1.63 & & .37 & .51 \\
Nickel & 1.70 & 6.71 & & 1.25 & 2.00 \\
Zinc & 75.4 & 66.1 & & 84.9 & 226 \\
\hline
\end{tabular}

quently, the relevant information source(s) should be consulted to ascertain the current values each time an analysis is performed (see urls in the references identified in the headnotes and footnotes of tables 5 and 6 ). If necessary, the tables and control charts should be updated to reflect the most recent values in a revised version of this SOP.

\section{Constructing the Control Charts}

1. Determine the contaminant, stretch, and species of interest. Separate control charts should be constructed for each contaminant, stretch, and monitored species. Use figure 2 as a guide.

2. Plot the mean and range (or individual sample values) of the contaminant of interest (on the y-axis) against time (on the $\mathrm{x}$-axis). Standard errors can be indicated by error bars surrounding each mean.

3. Determine a "center-line" value for the contaminant, which in general represents a long-term mean, a target value, or some other value. Here the most obvious "center-line" values are the 2005 concentrations for each stretch reported by Schmitt and others (2007b). Generally, determining an appropriate center-line value contains inherent pitfalls, and an analyst who is familiar with control charts should be consulted. In the context of this protocol, the center-line value is not as critical because the upper control limit is not based on any statistical property of the center-line.

4. Establish the upper control limit. (Lower control limits will not be necessary; low concentrations are not a concern.) The upper control limit will be the current dry-weight NEHC for the metal of interest in each taxon (table 6). It should be noted that control limits constructed in this way should be considered as "warning" limits rather than "action" limits because the thresholds represent NOAELs; the inherent assumptions (such as the receptor species consuming only the monitored species) will, therefore, likely result in conservative limits. For most metals, two such warning limits ideally would be indicated on each control chart: one representing the threshold for the small bird (robin) category, and a second representing the threshold for the small mammal (shrew) category. For cadmium, a third warning level representing the NEHC for amphibians also may be indicated.

5. Continue to plot values of the contaminant with time as new data become available. An observation that approaches or exceeds the warning limit(s) should trigger management concern. Any general increase with time in the contaminant concentrations beyond the 2005 baseline data (Schmitt and others, 2007b), even if below the warning limits, may be cause for concern. Update tables 5 and 6 and the control charts (and revise this SOP) as necessary. 
Table 6. No-effect hazard concentrations and safety factors of metals in crayfish (Orconectes spp.) and Asian clam (Corbicula fluminea) for receptor wildlife species.

[NEHC, no-effect hazard concentration; SF, safety factor; ww, wet weight; dw, dry-weight]

\begin{tabular}{|c|c|c|c|c|c|}
\hline Species & $\begin{array}{c}\text { NEHC } \\
(\mu \mathrm{g} / \mathrm{g} w w)^{1}\end{array}$ & $\begin{array}{c}\text { Crayfish NEHC } \\
(\mu \mathrm{g} / \mathrm{g} \mathrm{dw})^{1,2}\end{array}$ & Crayfish SF${ }^{1}$ & $\begin{array}{c}\text { Asian clam NEHC } \\
(\mu \mathrm{g} / \mathrm{g} \mathrm{dw})^{1,2}\end{array}$ & Asian clam SF ${ }^{1}$ \\
\hline \multicolumn{6}{|c|}{ Cadmium } \\
\hline Heron $^{4}$ & 8.2 & 40.8 & 53.0 & 54.4 & 16.3 \\
\hline Shrew $^{5}$ & 1.2 & 6.2 & 8.1 & 8.3 & 2.5 \\
\hline Robin $^{3}$ & 5.0 & 25.0 & 19.7 & 33.4 & 16.7 \\
\hline Heron $^{4}$ & 42.3 & 211 & 166 & 282 & 141 \\
\hline Shrew $^{5}$ & 11.8 & 59.1 & 46.5 & 78.8 & 39.4 \\
\hline Mink $^{6}$ & 52.4 & 262 & 206 & 349 & 175 \\
\hline Shrew $^{5}$ & 7.6 & 37.9 & 102 & 50.5 & 99.1 \\
\hline Mink $^{6}$ & 33.6 & 168 & 454 & 224 & 439 \\
\hline \multicolumn{6}{|c|}{ Nickel } \\
\hline Robin $^{3}$ & 4.4 & 22.1 & 17.7 & 29.4 & 14.7 \\
\hline Heron $^{4}$ & 37.3 & 186 & 149 & 249 & 124 \\
\hline Shrew $^{5}$ & 2.7 & 13.7 & 11.0 & 18.3 & 9.1 \\
\hline Mink $^{6}$ & 12.1 & 60.7 & 48.6 & 81.0 & 40.5 \\
\hline \multicolumn{6}{|c|}{ Zinc } \\
\hline
\end{tabular}

${ }^{1} \mathrm{NEHC}=$ Toxicity reference value (TRV)/daily food ingestion (DI); SF=NEHC/maximum 2005 concentration in crayfish and Asian clams from Ozark National Scenic Riverways (Schmitt and others, 2007c); all assuming a diet of 100 percent crayfish or Asian clam.

${ }^{2} \mathrm{dw}$ values computed assuming a moisture content of 80 percent for crayfish (Schmitt and others, 2006) and 85 percent for Asian clam (Belanger and others, 1986; Graney and Giesy, 1988; Jacomini and others, 2006).

${ }^{3}$ American robin, Turdus migratorius; DI=1.52 kg/kg/d (USEPA, 1993).

${ }^{4}$ Great blue heron, Ardea herodias; DI $=0.18$ kg/kg/d (USEPA, 1993).

${ }^{5}$ Short-tailed shrew, Blarina brevicauda; DI=0.62 kg/kg/d (USEPA, 1993).

${ }^{6}$ American mink, Mustela vison; DI=0.14 (USEPA, 1993). 


\section{Standard Operating Procedure 6: Reporting, Version 1.0 (July 28, 2008)}

\section{Revision History Log}

\begin{tabular}{|l|l|l|l|l|l|}
\hline $\begin{array}{c}\text { Previous version } \\
\text { number }\end{array}$ & Revision date & Author & Changes made & Reason for change & New version number \\
\hline & & & & & \\
\hline & & & & & \\
\hline & & & & & \\
\hline & & & & & \\
\hline
\end{tabular}

\section{Report Format}

\section{Template}

The report template for regional natural resource technical reports should be followed (http://www.nature.nps.gov/ publications/NRPM/index.cfm). Natural resource reports are the designated medium for disseminating high priority, current natural resource management information with managerial application. The NPS Natural Resource Technical Reports series is used to disseminate the peer-reviewed results of scientific studies in the physical, biological, and social sciences for the advancement of science and the achievement of the NPS mission.

\section{Style}

Standards for scientific writing as recommended in the Council of Science Editors (CSE) Style Manual (CSE, 2006) should be followed. Reports should be direct and concise. Authors of reports also should refer to Mack (1986), Goldwasser (1999), Strunk and White (2000), and Day and Gatsel (2006) for grammar and writing style.

\section{Types of Reports and the Review Process}

The HTLN monitoring plan (DeBacker and others, 2005) specifies that, for vital signs monitored annually, two main types of reports will be produced: annual status reports, and comprehensive trends and analysis and synthesis reports (every 5 to 7 years). Because metals monitoring will be conducted every 5 years, a modified reporting strategy is necessary; a report will be produced each time monitoring is conducted (every 5 years). This report will summarize the most recent monitoring results, provide an update on the status of selected natural resources, and highlight concerns that may require management action. It also should include a summary of data collected previously. After several monitoring events, it may be possible to begin to describe and interpret trends in metal concentrations. The primary audience for these reports will be park resource managers and external scientists. An Executive Summary, which highlights key points for nontechnical audiences, will be produced with each report. The primary audience for this Executive Summary will be Park Superintendents, interpreters, and the general public. Peer review for both will be conducted internally by HTLN staff.

\section{Report Distribution}

After review, annual reports will be distributed by September 1 of the year following data collection. Reports will be provided to ONSR, and a copy will be kept on file with the HTLN office of the National Park Service in Republic, Missouri, and can be made available to interested parties upon request. All data are public property and subject to requests under the Freedom of Information Act (FOIA); however, sensitive data, such as the location of rare species, must be withheld in some situations. Reports containing non-sensitive data will be disseminated through the HTLN network website (http://science.nature.nps.gov/im/units/htln/). 


\section{Standard Operating Procedure 7: After the Field Season, Version 1.0 (July 28, 2008)}

\section{Revision History Log}

\begin{tabular}{|l|l|l|l|l|l|}
\hline $\begin{array}{c}\text { Previous version } \\
\text { number }\end{array}$ & Revision date & Author & Changes made & Reason for change & New version number \\
\hline & & & & & \\
\hline & & & & & \\
\hline & & & & & \\
\hline & & & & & \\
\hline & & & & & \\
\hline
\end{tabular}

\section{Procedures}

1. Thoroughly clean, inspect, and repair or replace as necessary all equipment (such as nets, buckets, personal flotation devices, and boots) before storing it for future use. All reference manuals should be re-shelved on their appropriate bookshelf. Other reference materials and extra data sheets need to be filed in their appropriate filing cabinet. Clean the insides and outsides of all vehicles used in the field.

2. Organize field data sheets and check that they have been filled out completely. As a rule, all data sheets need to be reviewed for completeness before the crew leaves the field, then again as samples are logged in and frozen. However, because of the number of field days and crew members, some deficiencies in data recording may not be identified until all data sheets have been organized and reviewed as a group.

3. It also is best to enter data into computer files and verify the data as they are collected rather than letting it accumulate until after all the field work is done. This also is a good check on completeness, and will allow questions to be resolved while memories are fresh and personnel involved with the project are available. Ascertain that all data have been entered and verified by signing a "Supervisor Check" block on the Invertebrate Field Data Form.

4. When the laboratory data become available, check them over carefully and resolve any discrepancies before merging them with the field data. 


\section{Standard Operating Procedure 8: Revising the Protocol, Version 1.0 (July 28, 2008)}

\section{Revision History Log}

\begin{tabular}{|l|l|l|l|l|l|}
\hline $\begin{array}{c}\text { Previous version } \\
\text { number }\end{array}$ & Revision date & Author & Changes made & Reason for change & New version number \\
\hline & & & & & \\
\hline & & & & & \\
\hline & & & & & \\
\hline & & & & & \\
\hline
\end{tabular}

Personnel requested to edit the Protocol Narrative or any of the SOPs need to follow this procedure to eliminate confusion about how data are collected and analyzed. All personnel should be familiar with this SOP to identify and use the most current methodologies.

\section{Procedures}

1. This protocol and accompanying SOPs have attempted to incorporate the most sound methodologies for collecting and analyzing trace metal data. Nevertheless, all protocols require updating and editing as new and different information becomes available. Required edits should be made in a timely manner and appropriate reviews undertaken.

2. All edits require review for clarity and technical soundness. Small changes or additions to existing methods will be reviewed in-house by HTLN staff. However, if a complete change in methods is sought, an outside review is required. Regional and National NPS staff with familiarity in toxicology and data analysis will be utilized as reviewers. Experts outside of the NPS also will be utilized in the review process.

3. Document edits and protocol versions in the Revision History Log within the Protocol Narrative and each SOP. Log the changes in the Protocol Narrative or SOP being edited only. Version numbers increase incrementally (for example version 1.1 , version $1.2, \ldots$ ) for minor changes. Major revisions should be designated with the next whole number (version 2.0, version 3.0, version 4.0...). Record the previous version number, date of the revision, and author of the revision; identify paragraphs and pages where changes are made and the reason for making the changes; record the new version number.

4. Inform the Data Manager about changes to the Protocol Narrative or SOP so the new version number can be incorporated in the Metadata of the project database. The database may have to be edited by the Data Manager to accompany changes in the Protocol Narrative and SOPs.

5. Post new versions on the internet http://science.nature. nps.gov/im/monitor/protocoldb.cfm) and forward electronic copies to all known individuals in possession of a previous version of the affected Protocol Narrative or SOP.

\section{Acknowledgments}

This study was supported by the Contaminants Biology and Status and Trends of Biological Resources Programs of the U.S. Geological Survey and through an interagency agreement with the National Park Service. G. Linder and A.L. Allert provided useful comments on earlier versions of this report. 


\section{References Cited}

Allard, M., and Stokes, P.M., 1989, Mercury in crayfish species from thirteen Ontario lakes in relation to water chemistry and smallmouth bass (Micropterus dolomiueu) mercury: Canadian Journal of Fisheries and Aquatic Science, v. 46, p. 1,040-1,046.

Alikhan, M.A., Bagatto, G., and Zia, S., 1990, The crayfish as a "biological indicator" of aquatic contamination by heavy metals: Water Resources, v. 24, p. 1,069-1,076.

Allen, G.T., and Wilson, R.M., 1992, Trace elements and organic compounds in the Spring River basin of southeastern Kansas in 1988: Manhattan, Kansas, U.S. Fish and Wildlife Service, Contaminant Report No. R6/505M/91, $60 \mathrm{p}$.

Allert, A.L., Fairchild, J.F., DiStefano, R.J., Schmitt, C.J., Besser, J.M., Brumbaugh, W.G., and Poulton, B.C., 2008, Effects of lead-zinc mining on crayfish (Orconectes hylas) in the Black River watershed, Missouri: Freshwater Crayfish, v. 16 (in press).

Allert, A.L., Fairchild, J.F., Schmitt, C.J., Besser, J.M., Poulton, B.C., Brumbaugh, W.G., and DiStefano, R.J., 2005, Longitudinal characterization of stream communities downstream of lead mining in the Missouri Ozarks: Society of Environmental Toxicology and Chemistry, 26th Annual Meeting, November 13-17, Baltimore, Md. http://abstracts.co.allenpress.com/pweb/setac2005 document $/$ ID $=55713$

Anderson, M., and Thompson, A.A., 2004, Multivariate control charts for ecological and environmental monitoring: Ecological Applications, v. 14, p. 1921-1935.

Angelo, R., Cringan, M.S., Chamberlain, D.L., Stahl, A.J., Haslouer, S.G., and Goodrich, C.A., 2007, Residual effect of lead and zinc mining on freshwater mussels in the Spring River basin (Kansas, Missouri, and Oklahoma, USA): Science of the Total Environment, v. 384, p. 467-496.

Atkinson, A., Fisher, R.N., Rochester, C.J., and Brown, C.W., 2003, Sampling design optimization and establishment of baselines for herptofauna arrays at the Point Loma Ecological Reserve: U.S. Geological Survey, Western Ecological Research Center, Sacramento, California, 39 p. (http://www.werc.usgs.gov/sandiego/pdfs/PLER\%20 Sampling\%200ptimization\%207-23-04.pd)

Barks, J.H., 1978, Water quality in the Ozark National Scenic Riverways: U.S. Geological Survey Water-Supply Paper 2048, 57 p.
Bauch N.J., Schmitt, C.J., and Crawford, C.G., 2005, Development of an approach for integrating components of the U.S. Geological Survey Biomonitoring of Environmental Status and Trends (BEST) and National Stream Quantity Accounting Network (NASQAN) programs for large U.S. rivers: U.S. Geological Survey, Scientific Investigations Report 2005-5083, 53 p.

Baudrimont, M., Lapaquellerie, Y., Ribeyre, F., Maillet, N., Latouche, C., and Boudou, A., 1999, Field transplantation of the freshwater bivalve Corbicula fluminea along a polymetallic contamination gradient (River Lot, France): I. Geochemical characteristics of the sampling sites and cadmium and zinc bioaccumulation kinetics: Environmental Toxicology and Chemistry, v. 18, p. 2,462-2,471.

Beauregard, M.R., Mikulak, R.J., and Olson, B.A., 1992, A practical guide to statistical quality improvement: Opening up the statistical toolbox: Van Nostrand Reinhold, New York, N.Y., 469 p.

Belanger, S.E., Farris, J.L., Cherry, and D.S. Cairns, J., Jr., 1986, Growth of Asiatic clams (Corbicula sp.) during and after long-term zinc exposure in field-located and laboratory artificial streams: Archives of Environmental Contamination and Toxicology, v. 15, p. 427-434.

Besser, J.M., Brumbaugh, W.G., May, T.W., and Schmitt, C.J., 2007a, Biomonitoring of lead, zinc, and cadmium in streams draining lead-mining and non-mining areas, southeast Missouri: Environmental Monitoring and Assessment, v. 129 , p. 227-241.

Besser, J.M., Mebane, C.A., Mount, D.R., Ivey, C.D., Kunz, J.L., Greer, I.E., May, T.W., and Ingersoll, C.G., 2007b, Sensitivity of mottled sculpins (Cottus bairdi) and rainbow trout (Onchorhynchus mykiss) to acute and chronic toxicity of cadmium, copper, and zinc: Environmental Toxicology and Chemistry, v. 26, p. 1,657-1,665.

Besser, J.M., and Rabeni, C.F., 1987, Bioavailability and toxicity of metals leached from lead-mine tailings to aquatic invertebrates: Environmental Toxicology and Chemistry, v. 6, p. 879-890.

Beyer, W.N., Connor, E.E., and Gerould, S., 1994, Estimates of soil ingestion by wildlife: Journal of Wildlife Management, v. 58, p. 375-382.

Bowles, D., Luraas, J., Morrison, L., Dodd, H., Williams, M., Rowell, G., DeBacker, M., Hinsey, J., Usrey, F., and Haack, J., 2007, Protocol for monitoring aquatic invertebrates at Ozark National Scenic Riverways, Missouri, and Buffalo National River, Arkansas, Version 1.0: Fort Collins, Colorado, National Park Service, Heartland Inventory and Monitoring Network and Prairie Cluster Prototype Monitoring Program, Natural Resource Report NPS/HTLN/ NRR-2007/009, 138 p. (http://science.nature.nps.gov/im, units/htln/aquabugs.cfm) 
Brumbaugh, W.G., May, T.W., Besser, J.M., Allert, A.L., and Schmitt, C.J., 2007, Assessment of elemental concentrations in streams of the New Lead Belt in southeastern Missouri, 2002-05: U.S. Geological Survey, Scientific Investigations Report 2007-5057, $57 \mathrm{p}$.

Brumbaugh, W.G., Schmitt, C.J., and May, T.W., 2005, Concentrations of cadmium, lead, and zinc in fish from mining-influenced waters of northeastern Oklahoma: sampling of blood, carcass, and liver for aquatic biomonitoring: Archives of Environmental Contamination and Toxicology, v. 49, p. $76-88$.

Council of Science Editors Style Manual Committee, 2006, The CSE manual for authors, editors, and publishers, seventh edition: Reston, Virginia, $680 \mathrm{p}$.

Crawford, J.K., and Luoma, S.N., 1993, Guidelines for studies of contaminants in biological tissues for the National WaterQuality Assessment Program: U.S. Geological Survey, Open-File Report 92-494, 69 p.

Day, R.A., and Gastel, B., 2006, How to write and publish a scientific paper, sixth edition: Westport, Connecticut, Greenwood Press, 275 p.

DeBacker, M.D., Young, C.C. (editor), Adams P., Morrison L., Peitz D., Rowell G.A., Williams M., and Bowles D., 2005, Heartland Inventory and Monitoring and Prairie Cluster Prototype Monitoring Program vital signs monitoring plan: U.S. National Park Service, Heartland I\&M Network and Prairie Cluster Prototype Monitoring Program, Wilson's Creek National Battlefield, Republic, Missouri, 104 p.

DiStefano, R.J., 2005, Trophic interactions between Missouri Ozarks stream crayfish communities and sport fish predators: increased abundance and size structure of predators cause little change in crayfish community densities: Columbia, Missouri, Missouri Department of Conservation, Dingell-Johnson Project F-1-R-054, Study S-41, Job 4, Final Report, 128 p.

Dickson, G.W., Briese, L.A., and Giesy, J.P., 1979, Tissue metal concentrations in two crayfish species cohabiting a Tennessee cave stream: Oecologia, v. 44, p. 8-12.

Dwyer, F.J., Schmitt, C.J., Finger, S.E., and Mehrle, P.M., 1988, Biochemical changes in longear sunfish, Lepomis megalotis, associated with lead, cadmium and zinc from mine tailings: Journal of Fish Biology, v. 33, p. 307-317.

Fancy, S., 2001, Vital signs monitoring: a long-term commitment to protecting park natural resources: Chapter 1 in Natural resources year in review (http://www2.nature.nps. gov/YearInReview/yir2001/index.htm)
Farag, A.M., Woodward, D.F., Burmbaugh, W.G., Goldstein, J.N., MacConnell, E., Hogstrand, C., and Barrows, F.T., 1999, Dietary effects of metals-contaminated invertebrates from the Coeur d'Alene River, Idaho, on cutthroat trout: Transactions of the American Fisheries Society, v. 128, p. 578-592.

Foe, C., and Knight, A., 1987, Assessment of the biological impact of point source discharges employing Asiatic clams: Archives of Environmental Contamination and Toxicology, v. 16, p. $39-51$.

Gale, N., Adams, C.D., Wixson, B.F., Loftin, K.A., and Huang, Y.-W., 2004, Lead, zinc, copper, and cadmium in fish and sediments from the Big River and Flat River Creek of Missouri's Old Lead Belt: Environmental Geochemistry and Health, v. 26, p. 37-49.

Gillespie, R., Reisine, T., and Massaro, E.J., 1977, Cadmium uptake by the crayfish Orconectes propinquus (Girard): Environmental Science, v. 13, p. 364-368.

Goldhaber, M.B., Church, S.E., Doe, B.R., Aleinikoff, J.N., Brannon, J.C., Podosek, F.A., Mosier, E.L., Taylor, C.D., and Gent, C.A., 1995, Lead and sulfur isotope investigation of Paleozoic sedimentary rocks from the southern midcontinent of the United States; implications for paleohydrology and ore genesis of the Southeast Missouri lead belts: Economic Geology, v. 90, p. 1,875-1,910.

Goldwasser, L., 1999, A collection of grammatical points: Bulletin of the Ecological Society of America, v. 79, p. 48-150.

Goodyear, K.L., and McNeill, S., 1999, Bioaccumulation of heavy metals by aquatic macro-invertebrates of different feeding guilds: a review: Science of the Total Environment, v. 229 , p. 1-19.

Graney, R.L., Jr., Cherry, D.S., and Cairns, J., Jr., 1983, Heavy metal indicator potential of the Asiatic clam (Corbicula fluminea) in artificial stream systems: Hydrobiologia, v. 102, p. 217-222.

Graney, R.L., and Giesy, J.P., Jr., 1988, Alterations in the oxygen consumption, condition index, and concentration of free amino acids in Corbicula fluminea (Mollusca: Pelycopoda) exposed to sodium dodecyl sulfate: Environmental Toxicology and Chemistry, v. 7, p. 301-315.

Gunther, A.J., Davis, J.A., Hardin, D.D., Gold, J., Bell, D., Crick, J.R., Scelfo, G.M., Sericano, J., and Stephenson, M., 1999, Long-term bioaccumulation monitoring with transplanted bivalves in the San Francisco estuary: Marine Pollution Bulletin, v. 38, p. 170-181.

Gyrna, F.M., 2001, Quality planning and analysis: From product development through use: New York, McGraw-Hill Irwin, $752 \mathrm{p}$. 
Hinck, J.E., Schmitt, C.J., Echols, K.R., May, T.W., Orazio, C.E., and Tillitt, D.E., 2006, Environmental contaminants in fish and their associated risk to piscivorous wildlife in the Yukon River Basin, Alaska: Archives of Environmental Contamination and Toxicology, v. 51, p. 661-672.

Hirsch, R.M., Alley, W.M., and Wilber, W.G., 1988, Concepts for a national water-quality assessment program: U.S. Geological Survey Circular 1021, 42 p.

Hobbs, H.H. III, 1993, Trophic relationships of North American freshwater crayfishes and shrimps: Milwaukee, Wisconsin, Milwaukee Public Museum, 110 p.

Imes, J., 2002, Geohydrologic and biological investigations associated with a new lead-zinc exploration area near Winona, Missouri, and the Viburnum Trend of southeastern Missouri: U.S. Geological Survey Fact Sheet FS-005-02, $4 \mathrm{p}$.

Imes, J., Plummer, N.L., Kleeshculte, M.J., and Schumacher, J.G., 2007, Recharge area, base-flow and quick-flow discharge rates and ages, and general water quality of Big Spring in Carter County, Missouri, 2000-04: U.S. Geological Survey Scientific Investigations Report 2007-5049, $80 \mathrm{p}$.

Inza, B., Ribeyre, F., and Boudou, A., 1998, Dynamics of cadmium and mercury compounds (inorganic mercury or methylmercury): uptake and depuration in Corbicula fluminea. Effects of temperature and $\mathrm{pH}$ : Aquatic Toxicology, v. 43 , p. $273-285$.

Hopkins, WA, Roe, J.H., Snodgrass, J.W., Staub, B.P., Jackson, B.P., and Congdon, J.D., 2002, Effects of chronic dietary exposure to trace elements on banded water snakes (Nerodia fasciata): Environmental Toxicology and Chemistry, v. 21, p. 906-913.

Jacomini, A.E., Avelar, W.E.P., Martinez, A.S., and Bonato, P.S., 2006, Bioaccumulation of atrazine in freshwater bivalves Anodontites trapesialis (Lamrack, 1819) and Corbicula fluminea (Müller, 1774): Archives of Environmental Contamination and Toxicology, v. 51, p. 387-391.

James, S.M., Little, E.E., and Semlitsch, R.D., 2004, Effects of multiple routes of cadmium exposure on the hibernation success of the American toad (Bufo americanus): Archives of Environmental Contamination and Toxicology, v. 46, p. 518-527.

Joselow, M.M., 1980, Blood zinc and lead poisoning, in Nriagu, J.O. ed., Zinc in the environment, part II, health effects: New York, J. Wiley and Sons, p. 171-181.

Kleeschulte, M.J, and Sutley, S.J., 1995, Hydrologic data for the Fristoe Unit of the Mark Twain National Forest, Southern Missouri, 1988-93: U.S. Geological Survey Open-File Report 95-106, 106 p.
Knowlton, M.F., Boyle, T.P., and Jones, J.R., 1983, Uptake of lead from aquatic sediment by submersed macrophytes and crayfish: Archives of Environmental Contamination and Toxicology, v. 12, p. 535-541.

Leland, H.V., and Scudder, B.C., 1990, Trace elements in Corbicula fluminea from the San Joaquin River, California: Science of the Total Environment, v. 97/98, p. 641-672.

Linder, G., Bollman, M., Callahan, C., Gillette, C., Nebeker, A., and Wilborn, D., 1998, Bioaccumulation fond foodchain analysis for evaluating ecological risks in terrestrial and wetland habitats: availability-transfer factors (ATFs) in 'soil-soil macroinvertebrate-amphibian' food chains, in Hoddinott K, ed., Superfund risk assessment in soil contamination studies: Third Volume: Philadelphia, Pennsylvania, American Society of Testing and Materials ASTM STP 1338, p. 51-65.

Mack, R.N., 1986, Writing with precision, clarity, and economy: Bulletin of the Ecological Society of America, v. 67, p. 31-35.

Manly, B.F.J., 2001, Statistics for environmental science and management: Boca Raton, Florida, Chapman and Hall/ $\mathrm{CRC}, 326 \mathrm{p}$.

May, T.W., Wiedmeyer, R.H., Brumbaugh, W.G., and Schmitt, C.J., 1997, The determination of metals in sediment pore waters and in 1N HCl-extracted sediments by ICP-MS: Atomic Spectroscopy, v. 18, p. 133-139.

McBean, E.A., and Rovers, R.A., 1998, Statistical procedures for analysis of environmental monitoring data and risk assessment: Upper Saddle River, New Jersey, Prentice Hall PTR, 313 p.

McDonald, T., 2004, Ecological survey recommendations for the Buffalo National River and Ozark National Scenic Riverways Parks: Cheyenne, Wyoming, West, Inc., 15 p. (available online at http://science.nature.nps.gov/im/units/ htln/aquabugs.cfm)

McMahon, R.F., 1983, Ecology of an invasive pest bivalve, Corbicula, in Russell-Hunter, W.D., ed., The Mollusca, v. 6, Ecology: New York, Academic Press, p. 505-561.

Missouri Department of Conservation, 2007, Missouri species and communities of conservation concern checklist: Jefferson City, Missouri, Natural Heritage Program, 58 p.

Missouri Department of Health and Senior Services, 2008, 2008 Fish advisory. A guide to eating fish in Missouri: Jefferson City, Missouri, $11 \mathrm{p}$.

Momot, W.T., 1995, Redefining the role of crayfish in aquatic ecosystems: Reviews in Fisheries Science, v. 3, p. 33-63.

Montgomery, D.C., 2001, Introduction to statistical quality control: New York, J. Wiley and Sons, 776 p. 
Morrison, L.W., 2008, The use of control charts to interpret environmental monitoring data: Natural Areas Journal, v. 28 , p. $65-72$.

Muck, J.A., Rabeni, C.F., and Distefano, R.J., 2002, Reproductive biology of the crayfish Orconectes luteus (Creaser) in a Missouri stream: American Midland Naturalist, v. 147, p. $338-351$.

National Park Service, 2006, Inventory and monitoring natural resource database template version 3.1 documentation: Natural Resource Program Center, Office of Inventory, Monitoring, and Evaluation, Fort Collins, Colorado, 28 p.

Nagle, R.D., Rowe, C.L., and Congdon, J.D., 2001, Accumulation and selective maternal transfer of contaminants in the turtle Trachemys scripta associated with coal ash deposition: Archives of Environmental Contamination and Toxicology, v. 40, p. 531-536.

Nickerson, M., and Mays, C., 1973, The hellbenders: North American "Giant Salamanders": Milwaukee Public Museum, Publications in Biology and Geology, v. 1, p. $1-106$.

National Park Service Water Resources Division (NPS/ WRD), 2007, NPStoret. http://www.nature.nps.gov/water infoanddata/index.cfm\#NPSTORET

Oakley, K.L., Thomas, L.P., and Fancy, S.G., 2003, Guidelines for long-term monitoring protocols: Wildlife Society Bulletin, v. 31, p. 1,000-1,003.

Oesch, R.D., 1995, Missouri naiades, a guide to the mussels of Missouri: Jefferson City, Missouri, Missouri Department of Conservation, $271 \mathrm{p}$.

Olsen, A.R., Hayden, B.P., Ellison, A.M., Oehlert, G.W., and Esterby, S.R., 1997, Ecological resource monitoring: change and trend detection workshop report: Bulletin of the Ecological Society of America, v. 78, p. 11-13.

Petersen, J.C., Adamski, J.C., Bell, R.W., Davis, J.V., Femmer, S.R., Freiwald, D.A., and Joseph, R.L., 1998, Water quality in the Ozark Plateaus, Arkansas, Kansas, Missouri, and Oklahoma, 1992-95: U.S. Geological Survey Circular $1158,33 \mathrm{p}$.

Petersen, J.C., Justus, B.G., Dodd, H.R., Bowles, D.E., Morrison, L.W., Williams, M.H, and Rowell, G.A., 2007, Methods for monitoring fish communities of Buffalo National River and Ozark National Scenic Riverways in the Ozark Plateaus of Arkansas and Missouri: Version 1.0: U.S. Geological Survey Open-File Report 2007-1302, 94 p.

Petterson, M., 1998, Monitoring a freshwater fish population: statistical surveillance of biodiversity: Envirometrics, v. 9, p. $139-150$.
Parkyn, S.M., Collier, K.J., and Hicks, B.J., 2001, New Zealand stream crayfish: functional omnivores but trophic predators: Freshwater Biology, v. 46, p. 641-652.

Pflieger, W., 1996, The crayfish of Missouri: Jefferson City, Missouri, Missouri Department of Conservation, $152 \mathrm{p}$.

Probst, W.E., Rabeni, C.F., Covington, W.G., and Marteney, R.E., 1984, Resource use by stream-dwelling rock bass and smallmouth bass: Transactions of the American Fisheries Society, v. 113, p. 283-294.

Proctor, P.D., 1984, Heavy metal additions to the environment near mines, mills, and smelters, Southeast Missouri, in Nriagu, J.O., ed., Environmental impacts of smelters: New York, J. Wiley and Sons, p. 89-115.

Rabeni, C.F., Gossett, M., and McClendon, D.D., 1995, Contribution of crayfish to benthic invertebrate production and trophic ecology of an Ozark stream: Freshwater Crayfish, v. 10, p. 163-173.

Roldan, B.M., and Shivers, R.R., 1987, The uptake and storage of iron and lead in cells of the crayfish (Orconectes propinquus) hepatopancreas and antennal gland: Comparative Biochemistry and Physiology, Part C, v. 86, p. 201-214.

Rowell, G.A., Williams, M.H., and DeBacker, M.D., 2005, Data management plan: Heartland I\&M Network and Prairie Cluster Prototype Monitoring Program: Wilson's Creek National Battlefield, Republic, Missouri, 64 p.

Sample, B.E., Opresko, D.M., and Suter, G.W., 1996, Toxicological benchmarks for wildlife, 1996 revision: Oak Ridge, Tennessee, Oak Ridge National Laboratory, EX/ER/TM-86/ R3.

Sample, B.E., and Suter, G.W., 1999, Ecological risk assessment in a large river-reservoir: 4. piscivorous wildlife: Environmental Toxicology and Chemistry, v. 18, p. 610-620.

Schmitt, C.J., 2004, Concentrations of arsenic, cadmium, copper, lead, selenium, and zinc in fish from the Mississippi River basin, 1995: Environmental Monitoring and Assessment, v. 90, p. 289-321.

Schmitt, C.J., Brumbaugh, W.G., Linder, G.L., and Hinck, J.E., 2006, A screening-level assessment of lead, cadmium, and zinc in fish and crayfish from northeastern Oklahoma, USA: Environmental Geochemistry and Health, v. 28, p. 445-471.

Schmitt, C.J., Brumbaugh, W.G., and May, T.W., 2007a, Accumulation of metals in fish from lead-zinc mining areas of southeastern Missouri, USA: Ecotoxicology and Environmental Safety, v. 67, p. 14-30. 
Schmitt, C.J., Brumbaugh, W.G., May, T.W., and Besser, J.M., 2007b, Concentrations of metals in aquatic invertebrates from the Ozark National Scenic Riverways, Missouri: U.S. Geological Survey Open-File Report 2007-1435, 23 p.

Schmitt, C.J., Dwyer, F.J., and Finger, S.E., 1984, Erythrocyte $\delta$-aminolevulinic acid dehydratase (ALA-D) activity as an indicator of $\mathrm{Pb}$ and $\mathrm{Zn}$ bioavailability in a river contaminated by mine tailings: Canadian Journal of Fisheries and Aquatic Sciences, v. 41, p. 1,030-1,040.

Schmitt, C.J., and Finger, S.E., 1982, The transport, fate, and effects of trace metals in the Big and Black River watersheds, Southeastern Missouri: Columbia, Missouri, U.S. Fish and Wildlife Service, Columbia National Fisheries Research Laboratory, Project Completion Report to the St. Louis District, U.S. Army Corps of Engineers, St. Louis, Missouri, $167 \mathrm{p}$.

Schmitt, C.J., and Finger, S.E., 1987, The effects of sample preparation on the measured concentrations of eight elements in the edible tissues of fish contaminated by lead mining: Archives of Environmental Contamination and Toxicology, v. 16, p. 185-207.

Schmitt, C.J., Finger, S.E., May, T.W., and Kaiser, M.S., 1987, Bioavailability of lead and cadmium from mine tailings to the pocketbook mussel (Lampsilis ventricosa), in Neves, R.J., ed., Proceedings of the Workshop on Die-offs of Freshwater Mussels in the United States: Rock Island, Illinois, U.S. Fish and Wildlife Service and Upper Mississippi River Conservation Committee, p. 115-142.

Schmitt, C.J., Whyte, J.J., Brumbaugh, W.G., and Tillitt, D.E., 2005, Biochemical effects of lead, zinc, and cadmium from mining on fish in the Tri-States District of Northeastern Oklahoma: Environmental Toxicology and Chemistry, v. 24, p. $1,483-1,495$.

Schmitt, C.J., Whyte, J.J., Roberts, A.P., Annis, M.L., May, T.W., and Tillitt, D.E., 2007c, Biomarkers of metal exposure in fish from lead-zinc mining areas of southeastern Missouri, USA: Ecotoxicology and Environmental Safety, v. 67, p. $31-47$.

Schmitt, C.J., Wildhaber, M.L., Hunn, J.B., Nash, T., Tieger, M.N., and Steadman, B.L., 1992, Lead in Missouri streams: Monitoring pollution from mining with an assay for $\delta$-aminolevulinic acid dehydratase (ALA-D) in fish blood: Columbia, Missouri, U.S. Fish and Wildlife Service Field Office, $43 \mathrm{p}$.

Schmitt, C.J., Wildhaber, M.L., Hunn, J.B., Nash, T., Tieger, M.N., and Steadman, B.L., 1993, Biomonitoring of leadcontaminated Missouri streams with and assay for erythrocyte $\delta$-aminolevulinic acid dehydratase (ALA-D) activity in fish blood: Archives of Environmental Contamination and Toxicology, v. 25, p. 464-475.
Simberloff, D., 1998, Flagships, umbrellas, and keystones: is single-species management passé in the landscape era? Biological Conservation, v. 83, p. 247-257.

Stevens, D.L., Jr., and Olsen, A.R., 1999, Spatially restricted surveys over time for aquatic resources: Journal of Agricultural, Biological, and Environmental Statistics, v. 4, p. 415-428.

Stevens, D.L., Jr., and Olsen, A.R., 2004, Spatially balanced sampling of natural resources: Journal of the American Statistical Association, v. 99, p. 262-278.

Strunk, W. Jr., and White, E.B., 2000, The elements of style, fourth edition: New York, MacMillan, 105 p.

U.S. Environmental Protection Agency, 1989, Toxic Substances Control Act (TSCA); good laboratory practices standards; final rule: August 17, 1989, 49 CFR, Part 792.

U.S. Environmental Protection Agency, 1992, Framework for ecological risk assessment: Washington, D.C., EPA/630/ R-92/001.

U.S. Environmental Protection Agency, 1993, Wildlife exposure factors handbook: Washington, D.C., Office of Health and Environmental Assessment and Office of Research and Development, EPA/600/R-93/187. (http://cfpub.epa.gov/ ncea/cfm/wefh.cfm).

U.S. Environmental Protection Agency, 1997, Ecological risk assessment guidance for Superfund process for designing and conducting ecological risk assessments: Washington, D.C., EPA 540-R97-006, OS-WER 9285.7-25.

U.S. Environmental Protection Agency, 1998, Guidelines for ecological risk assessment: Washington, D.C., EPA/630/ R-95/002F.

U.S. Environmental Protection Agency, 1999, Screening level ecological risk assessment protocol for hazardous waste combustion facilities: Washington, D.C., Office of Solid Waste and Emergency Response (5305W), EPA 530D-99-001A.

U.S. Environmental Protection Agency, 2002, Guidance for quality assurance project plans, EPA-QA/G5, EPA/240/R02/009, December 2002, Office of Environmental Information, Washington, D.C.

U.S. Environmental Protection Agency, 2004, Contract laboratory program national functional guidelines for inorganic data review, OSWER/9240.1-45, EPA/540-R-04004, October 2004, Office of Superfund Remediation and Technology Innovation, Washington, DC. Available on-line at: http://www.epa.gov/superfund/programs/clp/download/ inorgfg 10-08-04.pdf 
U.S. Environmental Protection Agency, 2005a, Ecological soil screening levels for cadmium, Interim Final OSWER Directive 9285.7-65: Washington, D.C., Office of Solid Waste and Emergency Response, 211 p. plus appendices (http://www.epa.gov/ecotox/ecossl/).

U.S. Environmental Protection Agency, 2005b, Ecological soil screening levels for cobalt, Interim Final OSWER Directive 9285.7-67: Washington, D.C., Office of Solid Waste and Emergency Response, 57 p. plus appendices (http://www.epa.gov/ecotox/ecossl).

U.S. Environmental Protection Agency, 2005c, Ecological soil screening levels for lead, Interim Final OSWER Directive 9285.7-70: Washington, D.C., Office of Solid Waste and Emergency Response, 211 p. plus appendices (http://www.epa.gov/ecotox/ecossl/).

U.S. Environmental Protection Agency, 2007a, Ecological soil screening levels for nickel, Interim Final OSWER Directive 9285.7-76: Washington, D.C., Office of Solid Waste and Emergency Response, 113 p. plus appendices (http://www.epa.gov/ecotox/ecossl).

U.S. Environmental Protection Agency, 2007b, Framework for metals risk assessment: Washington, D.C., Office of the Science Advisor, EPA 120/R-07/001, 171 p. (http://oaspub.epa. gov/eims/eimscomm.getfile?p_download_id=461295).

U.S. Environmental Protection Agency, 2007c, Ecological soil screening levels for zinc, Interim Final OSWER Directive 9285.7-73: Washington, D.C., Office of Solid Waste and Emergency Response, 781 p. plus appendices (http://www.epa.gov/ecotox/ecossl).

Western Ecosystems Technology, Inc. (WEST), 2008. S-Draw Cheyenne, Wyoming http://www.west-inc.com/computer. php).
Whelan, G.E., 1983, The distribution and accumulation of lead and cadmium within a lotic benthic community: Columbia, Missouri, unpublished MS Thesis, University of MissouriColumbia, $157 \mathrm{p}$.

Whitledge, G., and Rabeni, C.F., 1997, Energy sources and ecological role of crayfishes in an Ozark stream: insights from stable isotopes and gut analysis: Canadian Journal of Fisheries and Aquatic Sciences, v. 54, p. 2,555-2,563.

Wildhaber, M.L., Schmitt, C.J., and Allert, A.L., 1997, Elemental concentrations in benthic invertebrates from the Neosho, Cottonwood, and Spring River systems of Missouri, Kansas, and Oklahoma: Columbia, Missouri, National Biological Service, Midwest Science Center, Project completion report to the U.S. Fish and Wildlife Service, Region 6, Manhattan, Kansas Ecological Services Field Office, $17 \mathrm{p}$.

Wixson, B.G., 1978, Biogeochemical cycling of lead in the New Lead Belt of Missouri, in Nriagu, J.O., ed., The biogeochemical cycling of lead in the environment, Part A. Ecological Cycles: Amsterdam, Elsevier/North Holland Biomedical Press, p. 119-136.

Wixson, B.G., and Jennett, J.C., 1975, The new lead belt in the forested Ozarks of Missouri: Environmental Science and Technology, v. 9, p. 1,128-1,133.

Woodling, J., Brinkman, S., and Albeke, S., 2002, Acute and chronic toxicity of zinc to the mottled sculpin Cottus bairdi: Environmental Toxicology and Chemistry, v. 21, p. $1,922-1,926$.

Woodward, D.F., Brumbaugh, W.G., DeLonay, A.J., Little, E.E., and Smith, C.E., 1994, Effects on rainbow trout fry of a metals-contaminated diet of benthic invertebrates from the Clark Fork River, Montana: Transactions of the American Fisheries Society, v. 123, p. 51-62. 


\section{Appendix 1. Invertebrate Field Data Form, Sample Labels, and Chain-of-Custody Record}



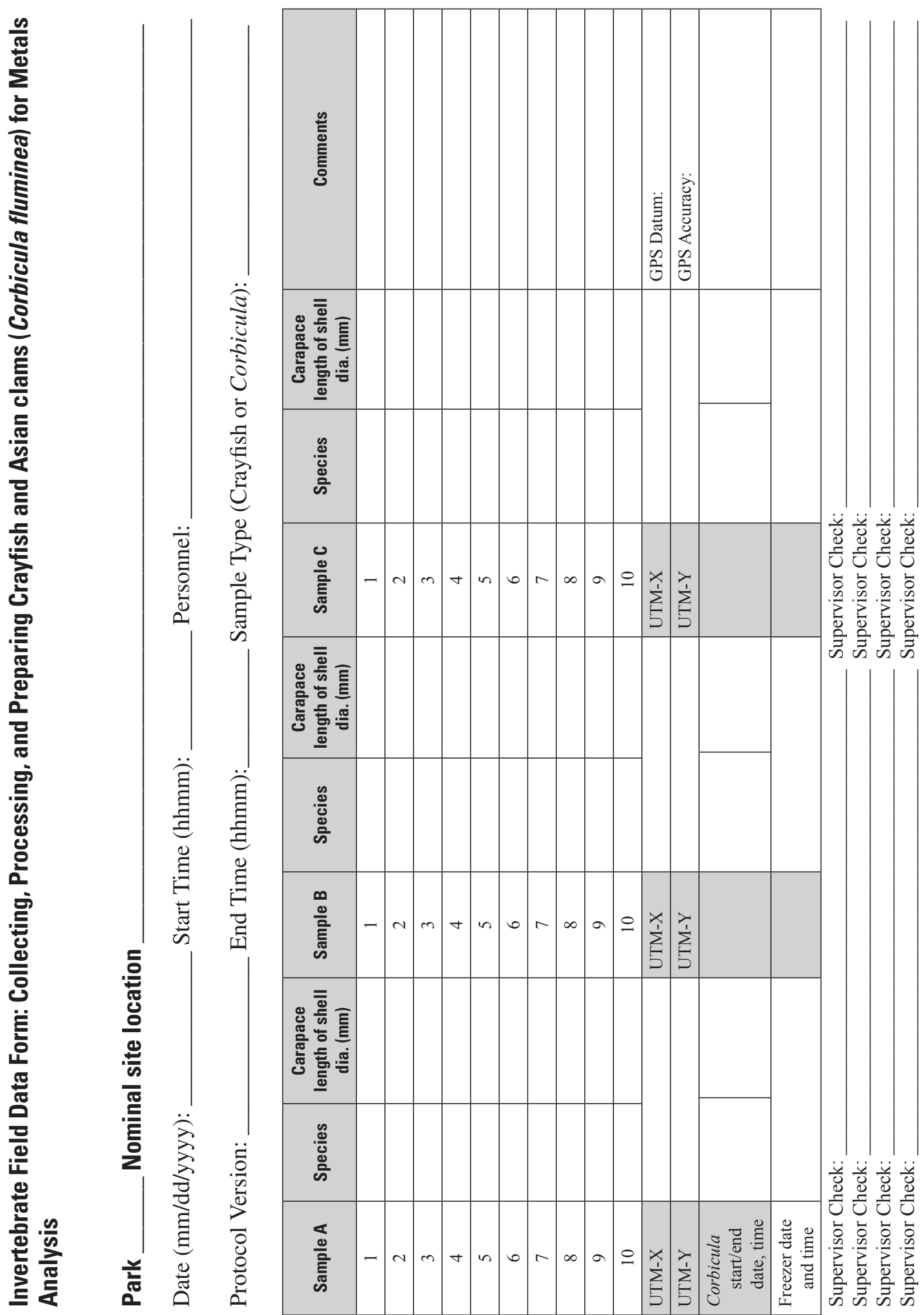

$\ddot{\ddot{y}} \ddot{\ddot{y}} \ddot{\ddot{y}}$ 过 范 $\geq \geq>>$

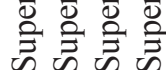




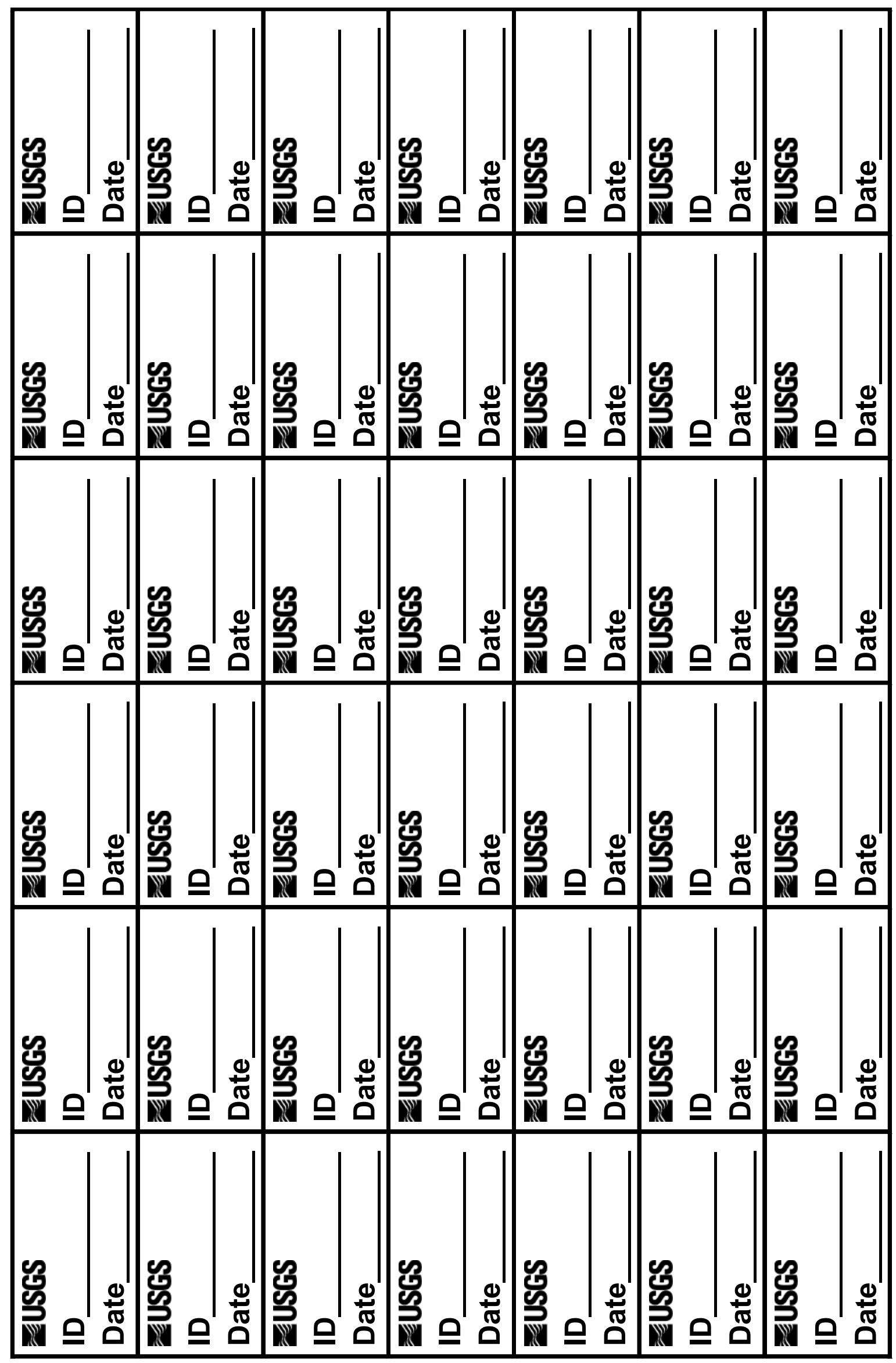




\section{₹USGS \\ Eusc}

\section{Chain-of-Custody Record}

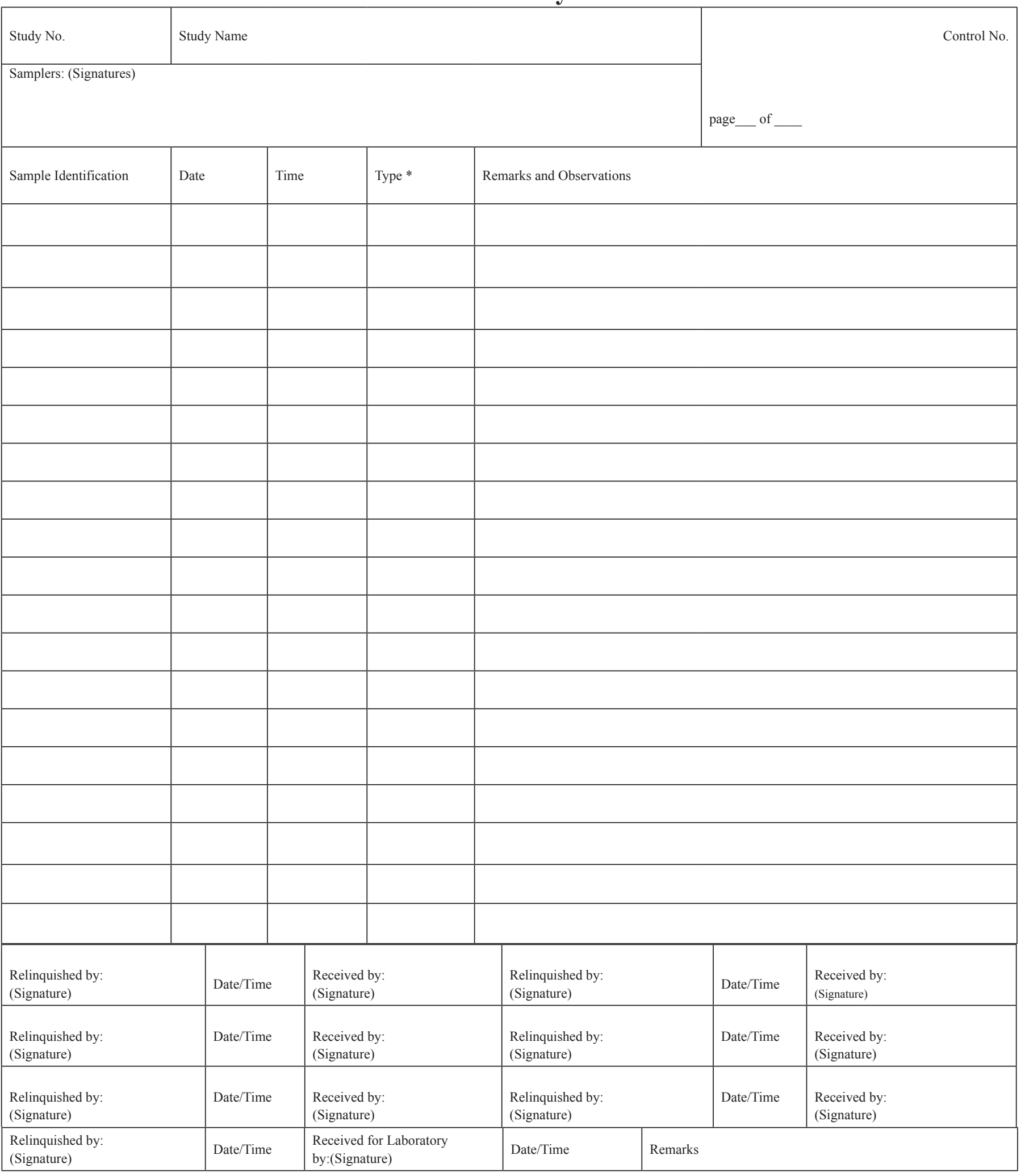

* $\mathrm{CR}=$ crayfish; $\mathrm{CO}=$ Asian clam $($ Corbicula $) ; \mathrm{O}=$ other, define in remarks 
Publishing support provided by:

Rolla Publishing Service Center

For more information concerning this publication, contact: Director, USGS Columbia Environmental Research Center 4200 New Haven Road

Columbia, MO 65201

(573) 875-5399

Or visit the Columbia Environmental Research Center Web site at: http://www.cerc.usgs.gov 
